IZA DP No. 9552

Same Program, Different Outcomes: Understanding Differential Effects from Access to Free, High-Quality Early Care Juan Chaparro Aaron Sojourner

December 2015 


\title{
Same Program, Different Outcomes: Understanding Differential Effects from Access to Free, High-Quality Early Care
}

\author{
Juan Chaparro
}

University of Minnesota

Aaron Sojourner

University of Minnesota

and IZA

\section{Discussion Paper No. 9552 \\ December 2015}

\author{
IZA \\ P.O. Box 7240 \\ 53072 Bonn \\ Germany \\ Phone: +49-228-3894-0 \\ Fax: +49-228-3894-180 \\ E-mail: iza@iza.org
}

\begin{abstract}
Any opinions expressed here are those of the author(s) and not those of IZA. Research published in this series may include views on policy, but the institute itself takes no institutional policy positions. The IZA research network is committed to the IZA Guiding Principles of Research Integrity.

The Institute for the Study of Labor (IZA) in Bonn is a local and virtual international research center and a place of communication between science, politics and business. IZA is an independent nonprofit organization supported by Deutsche Post Foundation. The center is associated with the University of Bonn and offers a stimulating research environment through its international network, workshops and conferences, data service, project support, research visits and doctoral program. IZA engages in (i) original and internationally competitive research in all fields of labor economics, (ii) development of policy concepts, and (iii) dissemination of research results and concepts to the interested public.
\end{abstract}

IZA Discussion Papers often represent preliminary work and are circulated to encourage discussion. Citation of such a paper should account for its provisional character. A revised version may be available directly from the author. 


\section{ABSTRACT \\ Same Program, Different Outcomes: Understanding Differential Effects from Access to Free, High-Quality Early Care*}

The Infant Health and Development Program (IHDP) was designed to promote the development of low-birth weight (up to 2,500 grams) and premature (up to 37 weeks gestational age) infants. There is evidence that the IHDP intervention, a randomly-assigned bundle of services including primarily free, high-quality child care from 12 to 36 months, boosted cognitive and behavioral outcomes by the time participants at the end of the intervention. The literature has established that the intervention was more effective among the subsample of heavier low birth weight (2,000-2,500 grams) than among those born lighter. Among the heavier group, it was more effective for children from lower-income families. Families who participated in the intervention were diverse in key observable characteristics like income, race or ethnicity. In addition, families reallocated their time in different ways when then had the opportunity to use the free services provided by the IHDP. The goal of this paper is to understand the economic decisions and constraints faced by households who gained access to the IHDP and explain their differential behavior. In order to do so, we propose an economic model, construct measures of theoretically-relevant drivers of postnatal investment decisions, and explore patterns of heterogeneity in parental response and child development along these dimensions.

JEL Classification: J13, J24, O15

Keywords: human capital, early childhood, experiment

Corresponding author:

Aaron J. Sojourner

Carlson School of Management

University of Minnesota

321 19th Ave S 3-300

Minneapolis, MN 55455

USA

E-mail: asojourn@umn.edu

\footnotetext{
* Many thanks to Greg Duncan for his advice throughout this project; Ana Auger, Jeanne BrooksGunn, Flavio Cunha, George Farkas, Kyoo II Kim, Maria Fernanda Rosales-Rueda, Jeffrey Smith, Chris Taber, Deborah Vandell, and Matt Wiswall for help developing these ideas and, especially, to Jade Jenkins for comments and help with the ECLS-B data. Research reported in this publication was also supported by the Eunice Kennedy Shriver National Institute of Child Health \& Human Development of the National Institutes of Health under Award Number P01HD065704. Support was also received from the Center for Personalized Prevention Research and the Human Capital Research Collaborative at the University of Minnesota through the 2014 Early Career Investigators Network Summer Fellowship. The content is solely the responsibility of the authors and does not necessarily represent the official views of the National Institutes of Health.
} 


\section{Introduction}

Evidence from human and animal studies shows that the brain develops critically-important neural structures and functions during pregnancy and the first few years after birth, which in turn shape long-run cognitive, social, emotional development and health outcomes (Sapolsky, 2004; Knudsen, Heckman, Cameron, \& Shonkoff, 2006). Moreover, brain development differs between children born into low-, middle-, and high-socioeconomic status (SES) families. Hanson et al. (2013) study of early brain structure development and find that the relationship between SES and average gray-matter volume is weak in the first year of life. However, large SES-based gaps emerge between ages 1 and 3 as average gray-matter volume becomes strongly and positively correlated with SES.

These structural differences are matched by the variation in behavioral measures of cognitive skills (e.g., IQ and achievement tests) assessed in the early years of children's lives. By age 5, reading and math achievement is strongly correlated with family income (Heckman, 2006; Reardon, 2011; Figlio, Guryan, Karbownik, \& Roth, 2014). Gaps in cognitive and other skills that exist at that point tend to persist throughout childhood and to have strong relationships with adult productivity (Cunha, Heckman, Lochner, \& Masterov, 2006).

Improving the quality of children's environments at very early ages can raise skill levels in both the short- and long-run (Committee on Integrating the Science of Early Childhood Development ,2000; Ramey, Campbell, \& Ramey, 1999; Duncan \& Magnuson, 2013). Compelling, policyrelevant evidence comes from experiments where, among participating families, some are randomly selected for the offer of free access to high-quality, early childhood care environments for their children along with supplementary services (treatment group) and other families are not (control group). The positive average treatment effects on child cognitive skill from many studies provide compelling evidence that environment matters for child development. While experimental designers and policy makers can offer particular programs to parents, the effects of these offers on children's development depend critically on how parents react to the offers. This paper examine the following questions theoretically and empirically:

- $\quad$ To what extent do families take up an offer of high-quality care during ages 12 to 36 months? 
- What kinds of environments are crowded out of the child's experience by the take-up? How do parents use any time freed by taking up the offer of free care?

- How does this combination of take-up and other choices affect child development?

- $\quad$ Furthermore, how do these choices differ across various kinds of families? What dimensions of children and families drive any differential responses?

The same treatment offer can have quite different effects on different kinds of children and families. Impacts on cognitive skill appear larger for children from lower-income families (Gormley, Phillips, \& Gayer, 2008; Duncan \& Sojourner, 2013; Cascio \& Whitmore Schanzenbach, 2013). Impacts also appear larger for children born heavier rather than very low birth weight (Gross, Spiker, \& Haynes, 1997). Heterogeneity on birth weight and family income are interesting and suggestive but neither dimension is ideal for understanding the fundamental economic choices that drive heterogeneity. For instance, birth weight reflects at least three distinct influences: characteristics of the family and mother fixed prior to pregnancy, choices that the mother made during her pregnancy that influence the child's condition at birth, and a random component that would generate differences in birth condition even among those with the same characteristics and prenatal choices. Family income also reflects at least three, distinct influences: an hourly wage available to any parent is largely set by a market outside their control, parents' choices about how many hours to work in the labor market, as well as sources of non-labor income. Two parents with the same potential wage and the same in other environmental circumstances may choose to work different numbers of hours and end up with different family incomes due to differences in the value they place on work, leisure, or parenting. Income reflects a choice. Potential wage is relatively fixed at a given point in time and summarizes the parent's expected labor-market productivity, which may be correlated with the parent's productivity in producing child skill through parenting as well.

Understanding what drives heterogeneous effects is essential to designing child-care or family subsidy policies. Policy implications depend on the extent to which differences in child-skill effects of offers of subsidized care are driven by differences in (a) the opportunity cost of parents' time (potential wage), (b) parents' willingness to expend available time, money, and effort to build children's skills rather than using those resources for other purposes holding 
other aspects of the situation fixed (tastes), or (c) biological differences fixed at birth (endowment) that may create differences in the productivity of postnatal influences. The current paper makes both theoretical and empirical contributions to understanding the drivers of heterogeneity in effects.

First, we propose a model of early childhood cognitive skill formation and maternal pre- and post-natal investment choice that combines features of some existing models (Ribar, 1995; Kimmel \& Connelly, 2006; Cunha, Heckman, \& Schennach, 2010; Bernal \& Keane, 2010; Gelber \& Isen, 2013), while adding key innovations including endogenous parenting effort and a framework for analyzing maternal and non-maternal care through a unified lens. The model is of a mother with one child. ${ }^{1}$ The child requires some type of care - either maternal or nonmaternal - at all times. The mother has a money budget, with expenditures split between nonmaternal child care and consumption, and a time budget split among labor-market work, parenting, and all other uses, which is broadly defined as leisure. Time spent providing maternal care requires foregoing wages and leisure. Each care type has an endogenous quality level, which is defined by how well it promotes the development of child cognitive skills. Higher quality and larger quantities of non-maternal care can be purchased with money. For a given mother, increasing maternal-care quantity or quality requires additional parenting effort. On the margin, additional parenting effort is a source of disutility for the mother. Integrating both parenting margins is a novel contribution of our paper and captures essential economic tradeoffs parents face. The model allows for heterogeneity in maternal tastes, maternal labor-market productivity, and maternal productivity in parenting, including possible correlations between labor market productivity and parenting productivity. We derive first-order conditions and corner solutions that characterize the optimal choices for trading off maternal leisure, consumption, parenting effort, and child-skill development. Maternal responses with respect to maternal time use, maternal parenting effort and maternal-care quality, quantities and qualities of nonmaternal care, and other margins are studied. The model illuminates important economic tradeoffs parents face and potential drivers of these choices.

\footnotetext{
${ }^{1}$ The theory could equivalently be framed as one parent and one child. However, in the data we analyze, there is careful attention paid to mothers. A maternal frame is used only for a smoother connection between theory and data. We regret any sexist overtones this generates.
} 
To develop empirical evidence, we study data from the Infant Health and Development Program (IHDP), which offered a package of services including free, full-day, Abecedarian-type early education to a randomly chosen subset of 985 children in eight sites scattered around the country (Bradley, et al., 1994; Gross, Spiker, \& Haynes, 1997). Eligible babies were born low birth-weight $(\leq 2,500 \mathrm{~g})$ and premature ( $\leq 37$ weeks gestation). Eligibility was not restricted by family income, race or ethnicity. A demographically-heterogeneous set of children and families enrolled in the study.

The IHDP treatment provided weekly home visits from a paraprofessional during the first year of life and up to nine hours of daily child care at an IHDP-run child development center (CDC) in each city when the child was age 12 to 36 months. The CDCs used a game-based curriculum that emphasized language development. A high-quality evaluation design included random assignment into treatment and assessment of intelligence quotient (IQ) and other outcomes. A series of papers reported treatment effects on various outcomes in various subsamples such as child cognitive skill and behavior (Brooks-Gunn, Klebanov, Liaw, \& Spiker, 1993), quality of the home environment (Bradley, et al., 1994), quality of parenting, maternal employment (Brooks-Gunn, McCormick, Shapiro, Benasich, \& Black, 1994), and the use of paid child care (Gross, Spiker, \& Haynes, 1997). Berlin, Brooks-Gunn, McCarton, \& McCormick (1998) studied mechanisms focusing especially on heterogeneity along demographic lines. They find that child cognitive effects are larger among those who take-up more care. Though the reducedform treatment effect of the IHDP intervention on child cognitive skill is known to vary by birth weight and maternal education and by income (Duncan \& Sojourner, 2013), there is more to learn about the channels creating this heterogeneity.

This paper contributes to the literature by studying heterogeneity in the IHDP along dimensions informed by economic theory. The IHDP provides a rich context to learn about heterogeneity in parental responses to an offer of free, high-quality care and how this relates to heterogeneity in child skill. First, the offered care constituted a powerful, positive shock to children's early environments on average. Second, it was randomly-assigned, generating credible causal identification. Third, the IHDP collected data on many margins of children's experiences, family characteristics, and parental choices for both the treatment and control groups. In some cases, the IHDP data does not contain explicit measures of theoretically-important factors and we construct proxies for these latent factors by combining IHDP data with supplementary 
sources. This permits us to carefully characterize families in theoretically-relevant dimensions that may drive heterogeneity in parental choices and provides many response margins to use as outcomes. Differences in parent's post-natal investment choices may be driven by a variety of differences including especially 1) differences in the value of their time in the labor market and in parenting (potential wage and productivity), 2) differences in their willingness and ability to expend available time, money, and effort to build child's human capital rather than to use those resources for other purposes holding fixed the amounts of resources available (tastes), and 3) differences in their child's condition at birth - weight or gestational age at birth - holding fixed observed family and prenatal influences.

Maternal potential wage is relatively straightforward to estimate using standard econometric methods. We do not directly observe mothers' wage in the IHDP, even for those who work. To build a wage proxy, we estimate a standard female labor supply model using a sample of mothers of young children from the Current Population Survey (CPS) over the same years. This delivers coefficients that relate expected potential wage to maternal and family characteristics, such as age, education level, marital status, and number of children of different ages. Using these coefficients, we score mothers in the IHDP using the same set of predictors to get a measure of each IHDP mother's expected potential wage.

There is not a standard way to disentangle differences in child condition at birth from differences in parental tastes. However, this is important in unpacking the drivers of heterogeneous treatment effects by birth weight. Parental tastes influence prenatal investment choices and, thereby, influence child condition at birth. Tastes continue to influence postnatal investment choices. Random shocks to conditions at birth can also have an independent effect on postnatal choices. For instance, consider a child born at particularly low weight or particularly premature compared to other children born in similar families by mothers who made similar prenatal investment choices; refer to this as a low level of child endowment or a bad shock to condition at birth. It is plausible that a parent would respond by adding extra, compensating investment, creating a negative correlation between child endowment and postnatal investments (Almond \& Mazumder, 2013). Looking at heterogeneity in postnatal investment choices by birth weight, it has not been clear whether the differences are due to differences in parental productivity, differences in maternal tastes, or differences in child endowment. 
Unlike postnatal investment choices, prenatal choices are made under a veil of ignorance with respect to child endowment (Aizer \& Cunha, 2012). Therefore, mothers' pre-natal investment choices - such as number of cigarettes smoked or amount of drugs and alcohol used during pregnancy - provide important information about maternal willingness to trade personal consumption utility against utility from future child human capital that is relatively uncontaminated by any post-natal reaction to information revealed at birth about the child's endowment. We develop a new method of disentangling parental tastes from child endowment based on this idea, which then allows us to measure each of these in each IHDP family and to study heterogeneity in effects along these lines.

We draw on the nationally-representative Early Childhood Longitudinal Study, Birth Cohort (ECLS-B) and estimate how prenatal investment choices and maternal characteristics predict birth weight and gestational age. Then, we score each mother-child pair in the ECLS-B on a pre-natal investment index and an index of child endowment, measured as the deviation of the child's realized birth status from its conditional expectation, yielding new nationallyrepresentative estimates of the joint distribution of indexes of pre-natal investment and child endowment. Next, we score each mother-child pair in the IHDP with this model and, thereby, characterize them in the national distribution in terms of prenatal investment level and child endowment. We consider the prenatal investment index as a proxy for maternal preference for child human capital in our analysis of postnatal investment choices and the child endowment as potentially important in governing the productivity of postnatal investments. Taken together, this gives a useful, theoretically-informed characterization of maternal and child type.

This approach is useful primarily because it allows us, when looking at children born at the same weight to demographically-similar mothers, to parsimoniously separate maternal tastes and child endowment. Children may end up at the same birth weight via low prenatal investment and high endowment shock or high investment and low shock.

In the end, we find evidence that measured heterogeneity in the opportunity costs of mothers' time is the most important in driving heterogeneous treatment effects while proxies for differences in maternal valuation of child human capital and biological differences fixed at birth explain much less. 


\section{Conceptual framework}

A public policy intervention, which has a standardized design and has been implemented uniformly across households, might produce different consequences among the participants. Such effect heterogeneity occurs because households react to policy interventions according to their preferences, resource constraints, and other factors. Our conceptual framework focuses on the economic decisions faced by participants in the IHDP about how to allocate their time, money, and effort between alternative uses, each of which has different consequences for parents and children. Households have different preferences about consumption, human development of their children, and time allocation between market and non-market activities. They also differ in the economic resources available to satisfy their needs. The conceptual framework brings together all these pieces in a one-period utility maximization problem, in which parents decide how to allocate their available resources to provide proper care to their child. We will refer to all care received by a child between birth and age 3 as postnatal investment.

\subsection{An economic model of post-natal investment}

Suppose early childhood cognitive skill is produced according to:

$$
h=\tilde{f}\left(I_{1}, h_{0}, \varepsilon\right) .
$$

In particular, allow age-3 IQ to depend on post-natal investment $\left(I_{1}\right)$, the stock of human capital at birth $\left(h_{0}\right)$, and unmeasured, post-natal productive heterogeneity $(\varepsilon)$. Cunha \& Heckman (2007) focused labor economists on trying to understand the dynamic complementarity of investments. Dynamic (or inter-temporal) complementarity captures how the productivity of current investment depends on the incoming stock of skill, embodying past investment and the innate endowment. In the present context, this key property of the human capital production function is $\tilde{f}_{12}=\frac{\partial^{2} \tilde{f}}{\partial I_{1} \partial h_{0}}$. It is interesting because it has a strong influence on the optimal timing of investments.

We also explore the productive relationship between two kinds of post-natal investments: embodied in maternal and non-maternal care. For child skill development, quality of care 
matters. Every child requires supervision and care for a total of $T_{c}=168$ waking hours per week, creating a child time budget. This is common across all children.

$$
\left.r+n+t=T_{c} \quad \text { (1: child time constraint }\right)
$$

The distribution of developmentally-relevant care quality and type varies. Allowing for the possibility that maternal care is special, we consider two kinds of care: maternal and nonmaternal such that maternal care hours $(r)$ plus non-maternal care hours $(n)$ must total $T_{c}$. This constitutes the child's time budget constraint. Non-maternal care encompasses many arrangements, such as care by other relatives or purchased child care services. The qualities of maternal care $\left(q^{r}\right)$ and non-maternal care $\left(q^{n}\right)$ also vary. Post-natal investment depends on quality-adjusted effective units of maternal and non-maternal care:

$$
I_{1} \equiv g\left(q^{n} n, q^{r} r\right)
$$

In the context of the IHDP, a special source of non-maternal care is available to those in the treatment group. Households in the treatment group can use the child development center (CDC) services for up to $\bar{\tau}=45$ hours per week. Mothers choose how many hours to take up.

$$
t \leq \bar{\tau} \quad(2: \text { maximum CDC time })
$$

In the control group, no CDC hours are available, $\bar{\tau}=0$. The quality of free CDC daycare is exogenous and equal to $q^{t}$. Effective units of CDC care are equal to $q^{t} t$. Effective units of nonmaternal care become the sum of effective units of CDC care and other nonmaternal care: $q^{t} t+$ $q^{n} n$. Effective units of care are a central concept in the model and Table 1 summarizes them. These are the investment inputs of the child's human capital production function. Combining $\tilde{f}$ and $g$ yields the production function.

$$
h=f\left[q^{n} n+q^{t} t ; q^{r} r ; h_{0}, \varepsilon\right](3: \text { human capital production technology) }
$$

Each mother also has a time constraint (Eq. 4). She divides her time endowment $\left(T_{p}\right)$ between three types of activities. Maternal child care $(r)$, as previously discussed, is one. Leisure $(l)$ and wage work $(L)$ are the others.

$$
r+L+l=T_{p} \quad(4: \text { mother's time constraint) }
$$


The mother can earn a potential wage per hour $(w)$, which is an increasing function of observed human capital $(m)$ and unobserved ability $(\omega)$ :

$$
w=w(m, \omega) \quad \text { (5: wage offer) }
$$

Total income equals labor earnings plus any exogenous non-labor income $(Y)$. Total income can be used to purchase child care in the market or to pay for consumption (c). Regarding nonmaternal, non-CDC sources of care, mothers choose both how much time to use $(n)$ and the quality of care $\left(q^{n}\right)$. These have a non-negative and exogenous price equal to $\pi$ per each unit of effective care received.

$$
c+\pi q^{n} n=w L+Y \quad \text { (6: Budget constraint) }
$$

The quality of maternal care $\left(q^{r}\right)$ depends on the mother's human capital $(m)$, unobserved individual heterogeneity in ability $(\omega)$, and instantaneous parenting effort $(e)$ :

$$
q^{r}=q^{r}(m, \omega, e) \quad(7: \text { maternal-care quality technology) }
$$

This allows the wage offer $(w)$ and the quality of maternal care $\left(q^{r}\right)$ to be correlated due to observed maternal characteristics, like maternal education or unobserved maternal heterogeneity in ability. We assume $(m, \omega)$ are given but mothers choose the level of parenting effort they invest.

Maternal preferences are represented by $U(c, l, p, h, t)$. Utility increases in consumption $(c)$, leisure hours $(l)$, and the child's human capital $(h)$, but decreases in total parenting effort $(p)$ and time the child spends at the $\mathrm{CDC}(t)$. The mother chooses $\left(c, q^{n}, n, e, r, l, L, t\right)$. Total parenting effort is the product of the instantaneous effort level $(e)$ and effort duration, that is hours of maternal care provided $(r)$.

$$
p=e r \quad \text { (8: Total parenting effort) }
$$

This parenting quality-quantity tradeoff has been missing from the economics literature, perhaps because datasets with both parenting time and parenting quality are rare. This captures the idea 
that high-quality parenting is more difficult to maintain over longer periods than shorter periods. Parenting can be exhausting. ${ }^{2}$

Some distaste for free CDC services is required to explain incomplete take-up of high-quality, free care, similar to Bernal and Keane (2010). This distaste captures individual heterogeneity in felt stigma or logistical challenges in using the CDC, such as perhaps working nights or having multiple young children, with only one eligible for CDC care.

A full income - full consumption budget constraint is obtained by combining equations 1,4 and 6. This simplifies the constraints and yields the following expression:

$$
c+\left[\pi q^{n}-w\right] n+w l=w\left[T_{p}-T_{c}\right]+w t+Y
$$

Full income, which corresponds to the right hand side of (9), is derived from non-labor income, total free daycare time valued at the parent's market wage and net parental time endowment, also valued at the market wage. On the other hand, full consumption has three components. The first one is traditional consumption. The second one is total value of other sources of care, like purchased daycare. Focus on the economic cost of this decision, which is $\pi q^{n}-w$ : one additional hour of daycare with quality $q^{n}$ will cost the parent a total of $\pi q^{n}$ monetary units, but this decision will free up one hour of parental time, which has a labor market value of $w$. The third component of full consumption is leisure time priced at the market wage. We can now write the post-natal problem as:

$$
\begin{array}{ll}
\operatorname{Max}_{c, q^{n}, e, n, l, t} U(c, l, p, h, t) & \\
\text { s.t. } & c+\left[\pi q^{n}-w\right] n+w l=w\left[T_{p}-T_{c}\right]+w t+Y \\
& h=f\left[q^{n} n+q^{t} t ; q^{r} r ; h_{0}, \varepsilon\right] \\
& t \leq \bar{\tau} \quad p=e r
\end{array}
$$

\footnotetext{
${ }^{2}$ The utility function assumes a negative marginal utility to parenting effort. What about the possibility that parents derive positive utility from parenting? The focus is here on the margin, not on the first hour of parenting. Conventional labor-leisure choice models assume that the marginal utility of labor is negative, despite the fact that we might enjoy the first hour of our jobs. This assumption on parenting is similar. If there were no cost to parenting effort, we would get unboundedly high parenting time and effort. Everyone chooses a positive level of leisure hours. Another way of understanding this is to say that maybe there is both an indirect utility payoff from parenting effort through increased child human capital (which we capture) and a direct payoff (which we shut down). Any direct payoff will be interpreted as an especially high taste for child human capital.
} 


\subsection{Optimal post-natal investment and economic interpretation}

This section describes properties of the optimal choices formally and discusses the economic tradeoffs behind these decisions. The solution to the post-natal parental problem is given by a vector of eight variables $\left(\lambda^{*}, \mu^{*}, c^{*}, q^{n *}, e^{*}, n^{*}, l^{*}, t^{*}\right)$ which comply with all the Kuhn-Tucker conditions available in Appendix 1. Optimal labor supply $\left(L^{*}\right)$ and optimal parental care $\left(r^{*}\right)$ will be given by:

$$
r^{*}=T_{c}-n^{*}-t^{*} \quad L^{*}=T_{p}-l^{*}-r^{*}
$$

The following expressions are based on the Kuhn-Tucker conditions, but use the marginal rates of substitution (MRS) which are more suitable for economic interpretation. These first order conditions focus on solutions where the budget constraint is binding $\left(U_{c}=\lambda^{*}>0\right)$ and parents do not use all the hours available for them at the CDC $\left(0 \leq t^{*}<\bar{\tau} ; \mu^{*}=0\right)$, because this is a predominant characteristic in the IHDP data. We contemplate cases where the mother could decide not use help from other caretakers $\left(n^{*} \geq 0\right)$. Finally, for a more transparent presentation of the first order conditions, we will focus only on interior solutions for $c^{*}, q^{n *}, e^{*}$ and $l^{*}$.

$\frac{\partial \mathcal{L}}{\partial l}: \quad M R S_{l, c}=w$

$\frac{\partial \mathcal{L}}{\partial t}: \quad M R S_{h, c}\left[f_{1} q^{t}-f_{2} q^{r}\right]+w-M R S_{p, c} e \leq-M R S_{t, c} \quad \frac{\partial \mathcal{L}}{\partial t} t=0 \quad 0 \leq t<\bar{\tau}$

$\frac{\partial \mathcal{L}}{\partial n}: M R S_{h, c}\left[f_{1} q^{n}-f_{2} q^{r}\right]+w-M R S_{p, c} e \leq \pi q^{n} \quad \frac{\partial \mathcal{L}}{\partial n} n=0 \quad n \geq 0$

$\frac{\partial \mathcal{L}}{\partial q^{n}}: f_{1} M R S_{h, c}=\pi$

$\frac{\partial \mathcal{L}}{\partial e}: \quad f_{2} q_{e}^{r} M R S_{h, c}=-M R S_{p, c}$

Equations (A), (B) and (C) determine all optimal time decisions. Like in any other traditional labor supply model, optimal leisure is given by the equality of the market wage rate and the marginal rate of substitution between leisure and consumption (A).

Equation (B) explains the decision to use the free services from the CDC. Possible marginal benefits are on the left hand side of the inequality. Marginal costs are on the right hand side. The effect of one additional hour at the CDC on the child's human capital will depend on the 
quality gap between maternal and CDC care, which is equal to $f_{1} q^{t}-f_{2} q^{r}$. The first term $\left(f_{1} q^{t}\right)$ measures the raw marginal effect of CDC time on the child's human capital, but such an event implies that the child spent one less hour with her mother. Therefore, we must subtract the marginal effect of maternal time on the child's human capital $\left(f_{2} q^{r}\right)$ to determine the final effect. Notice that the quality gap could be either positive or negative, and it is valued by the mother using her marginal rate of substitution between human capital and consumption $\left(M R S_{h, c}\right)$. Use of services from the CDC also imply that the mother could work additional hours paid at the market wage rate $w$. Increasing CDC use also implies less total parental effort (er) needs to be exerted and, so, it can provide some relief from parenting effort. This possible relief is valued using the marginal rate of substitution between parental effort and consumption $\left(M R S_{p, c}\right)$. Although the CDC offers a free service, there may be an implicit cost generated by participation stigma or by associated logistical challenges. This cost is captured by the marginal rate of substitution between time spent at the $\mathrm{CDC}$ and consumption $\left(M R S_{t, c}\right)$.

Optimal non-maternal and non-CDC care time is given by $(\mathrm{C})$. Note its similarity with the decision rule for use of CDC services. In this case, what matters is the quality gap between other caregivers and maternal care, $f_{1} q^{n}-f_{2} q^{r}$. Another difference lies in the financial expenditure measured by $\pi q^{n}$.

Recall that quality of care is endogenous in this model. Quality of non-maternal, non-CDC care $\left(q^{n}\right)$ is determined by (D). (E) explains the decision of optimal parenting effort $(e)$, which is the key choice behind quality of maternal care $\left(q^{r}\right)$. In both cases, the marginal return to additional quality depends on the human capital technology. The marginal productivity of non-maternal care $\left(f_{1}\right)$ measures the benefits of additional quality from this type of caregiver. Extra maternal effort translates into additional human capital in the child depending on the marginal productivity of maternal care $\left(f_{2} q_{e}^{r}\right)$. Both marginal effects must be valued using the marginal rate of substitution between the child's human capital and consumption $\left(M R S_{h, c}\right)$. Recall that $\pi$ is the price of one unit of effective care by a caregiver different than the mother or the CDC. The implicit price of maternal effort is measured using the marginal rate of substitution between parental effort and consumption $\left(M R S_{p, c}\right)$.

What do these conditions suggest about the key drivers of the decision of how many hours of free CDC care to take-up and how to adjust on other margins? First, potential wage $(w)$ is key as 
both a proxy for the value of an extra hour doing something besides maternal care and, if productivity in the labor market and in parenting are correlated, also for differences in the productivity of maternal-care time $\left(f_{2} q^{r}\right)$. Potential wage influences the CDC take-up decision problem in countervailing ways. On one hand, a higher wage increases the potential consumption or leisure benefit of the freed up maternal hour and would encourage take up through this channel. On the other hand, a higher wage may imply that each hour of maternal care is potentially more-productive and shrink the child-development benefit of CDC use by making the quality-gap smaller, consistent with the findings of Bernal \& Keane (2011). Second, differences in the ways that parents balance competing priorities against the costs of investment in child skill $\left(M R S_{h, c} ; M R S_{p, c}\right)$ may help explain they make different take-up choices. Finally, the productivity of postnatal investments $\left(f_{1}, f_{2}\right)$ in producing child skill may depend on the child condition at birth and the endowment shock that the child experienced.

Factors that the model identifies as driving postnatal investment decisions inform our analysis of the IHDP data. Unlike family income, these three factors are fixed at the time of the child's birth, which is also the time of random assignment to treatment. We study heterogeneity in treatment effects along these dimensions on numerous postnatal choices that mothers make that influence child development: maternal care quantity and quality, non-maternal care quality and quantity, maternal market-labor hours, and maternal leisure hours.

\section{Data and variables}

3.1 Factors examined for heterogeneity in effects: potential wage $(\widehat{w})$, pre-natal investment level $\left(I_{0}^{*}\right)$, and child's endowment $(\phi)$

The IHDP contains many variables that should be informative about potential wage, prenatal investment, and child's endowment but not direct measurement of these factors alone. We harness outside information to develop measures of each variables of interest for each individual in the IHDP. The basic approach is to estimate a model in the outside dataset and 
then score each IHDP observation using the model's estimated parameters. That is, we impute conditional means in place of missing values. ${ }^{3}$

\subsubsection{Potential wage $(\widehat{w})$}

Rather than focusing on income, which combines wage, hours of work, and non-labor sources of income, the present study focuses on differences in effects based on mother's potential wage as predicted by characteristics fixed at the time of random assignment. Potential wage ties directly to economic tradeoffs mothers face in how they use their time.

We assume that potential wage depends on observed and unobserved maternal characteristics. Using a Heckman selection model estimated in a similar Current Population Survey sample, based on variables available in both the CPS and IHDP, we obtain the expected potential wage, $\widehat{w}(m)$, for a mother with a given set of observables $(m)$.

We use the Current Population Survey March supplements for 1986-89 from MPC-IPUMS (Flood, King, Ruggles, \& Warren, 2015). We limit the sample to mothers between the ages of 15 and 55 with at least one child below the age of 5, excluding non-civilians, unpaid family workers, and the self-employed. In terms of cleaning and modeling, we largely follow Mulligan $\&$ Rubinstein (2008). However, we include women of color and allow wage offers and employment probabilities to differ by ethnicity. Observed hourly wage is the ratio of last year's total labor income divided by usual hours per week times weeks worked. Wages below $\$ 3.73$ and above $\$ 80$ in 2012 dollars are trimmed.

\footnotetext{
${ }^{3}$ This is different than mean-imputation or multiple-imputation as usually practiced. Usually, the problem is that, within a single dataset, a variable (x) has some individuals with observed values and other individuals with missing values. Let $\mathrm{z}$ indicate whether the value is observed for each individual. Typically, other variables (d) have fullyobserved values. In this case, researchers often model the relationship between the variable with some missing values and the variables with fully-observed values in the subsample where $\mathrm{x}$ is observed $(\mathrm{z}=1)$. Then, the subsample where $\mathrm{x}$ is missing $(\mathrm{z}=0)$ are scored and this is used to impute missing values and the primary relationship of interest, $\mathrm{E}[\mathrm{y} \mid \mathrm{x}]$, is then estimated using the full sample. While this can produce unbiased estimates under some conditions, the conditions are often not credible. Some selection process drove some individuals to have missing values and others to have observed values. This selection process might also affect the primary relationship of interest and lead to bias. Our situation is different. Here, all individuals have missing data on the variables in question. There is no selection into observability. The original IHDP researchers collected data on a huge number of variables but missed a few specific variables that we care about. We are harnessing the outside data to understand the relationship between observables in both datasets and the missing variables of interest. Then, we use the conditional mean prediction as an imputed proxy for the missing values.
} 
The mothers who participated in the IHDP are not a representative sample for the United States. They have different demographic and socioeconomic profiles, when compared to the rest of the country. As evidence consider Table 2, which compares basic characteristics from the IHDP and the CPS samples. Around $80 \%$ of the women included in the CPS were married; this was the case for only $46 \%$ of the women in the IHDP sample. Most of the mothers in the CPS sample were Non-Hispanic Whites (70\%), whereas most of the IHDP mothers were African American (52\%). The IHDP participants also had, on average, less schooling and less potential experience in the labor market.

We use a standard Heckman model of selection into the workforce $(L=1)$ estimated by the 2step method (Heckman, 1974):

$$
\begin{gathered}
\ln (w)=X \beta^{w}+\theta^{w} \lambda\left(Z \delta^{w}\right)+\epsilon^{w} \\
\operatorname{Pr}(L=1 \mid Z)=\Phi\left(Z \delta^{w}\right)
\end{gathered}
$$

Wage determinants $(X)$ are potential work experience, indicators of educational attainment, ethnicity, and marital status. ${ }^{4}$ To capture differences in local-market conditions, we include an indicator for residence in each of the 8 IHDP site's metropolitan areas, an indicator for other SMSA residency and indicators for region and year.

The participation determinants $(Z)$ include all components of $X$ as well as the following variables, which are excluded from the wage equation: number of children below age 5, age of the youngest child and number of other children in household. ${ }^{5}$ The Heckman selection model produces estimates for $\beta^{\mathrm{w}}, \delta^{\mathrm{w}}$ and $\theta^{\mathrm{w}}$, which are reported in Table 3 . The first column corresponds to the wage equation and the second column reports the selection equation. The results from the Heckit model are sensible and consistent with the literature. ${ }^{6}$ These estimates

\footnotetext{
${ }^{4}$ Potential work experience is defined as maximum $\{0$, age - years of completed schooling - 7$\}$. All the way up to quartic term in included, in addition to interactions with education attainment indicators. Less than high school; high school only (women who finished 12th grade, have a high school diploma or equivalent); some college (between one and three years of college education); college graduate (four or more years of college education). High school only is the omitted category. Non-Hispanic Whites; African-American; Hispanic; Other. Non-Hispanic White is the omitted category. Never-married; Married; Separated / Widowed / Divorced. Married is the omitted category.

${ }^{5}$ We also include the interaction of these three variables with the marital status indicators. Observations with any demographic variables missing are dropped.

${ }^{6}$ Potential experience and having a college degree increase the probability of working and rise the potential wage. The number of children under the age of 5 reduces the probability of working for wages. The number of children in
} 
are used to predict an expected potential wage for each mother in the IHDP sample, treating the estimates as known parameters. ${ }^{7}$ The first rows of Table 2 summarize the results. The average potential wage for working mothers in the CPS sample is equal to $\$ 13.46$ per hour, whereas it is $\$ 8.08$ for working mothers and $\$ 6.62$ for all mothers in the IHDP. ${ }^{8}$

\subsubsection{Pre-natal investment $\left(I_{0}^{*}\right)$ and child's endowment $(\phi)$}

To separately measure two key determinants of birth conditions, prenatal investment levels and child endowment, we characterize the IHDP sample in the national distribution by drawing on data from the ECLS-B while controlling for common demographic determinants of birth conditions. To capture this relationship, we assume that a prenatal production function maps observed maternal characteristics that would influence fetal development and maternal beliefs $(X)$, latent prenatal investments $\left(I_{0}^{*}\right)$, and the child's idiosyncratic endowment $(\phi)$ into $h_{0}$. Assume the function is linear,

$$
h_{0} \equiv \pi_{0}+\pi_{1} I_{0}^{*}+\pi_{2} X+\phi
$$

Also, assume $\phi$ is mean independent of $I_{0}^{*}$, conditional on $X$. This assumption is credible given that $I_{0}^{*}$ is chosen pre-natally, before information about child endowment $\phi$ is known to the mother (Aizer \& Cunha, 2012).

We seek to understand these relationships in the Early Childhood Longitudinal Study - Birth cohort (ECLS-B), the nation's first nationally-representative birth cohort consisting of approximately 14,000 children born in 2001 (Nord, Edwards, Andreassen, Green, \& WallnerAllen, 2006). ${ }^{9}$ To approximate $\left(I_{0}^{*}, \phi\right)$, we proxy $h_{0}$ with the two birth outcomes on which the IHDP sample is selected: weight $(W)$ and gestational age $(A)$. In a SUR framework, we regress

\footnotetext{
the household who are older than 5 years also reduced the probability, but by about half as much. Most importantly, the inverse mills ratio (Lamda) has a significant negative coefficient, suggesting it is correcting for selection into the labor force.

${ }^{7}$ We exclude geographic variables when scoring the IHDP sample in order to focus the variation in potential wage on human capital and family, rather than cross-site differences in cost of living and wage levels. We include site dummies in all outcome models. We follow Cameron \& Trivedi (2010, pp. 562 - 565) on how to calculate the predicted value from a selection model in which the outcome of interest is in logs.

${ }^{8} \log (13.46)=2.60$

${ }^{9}$ Because the IHDP sample is selected on explicit thresholds for birth weight and gestational age, studying the relationship between $I_{0}^{*}$ and $h_{0}$ in the IHDP sample directly would produce misleading conclusions.
} 
each of these birth outcomes on a vector of observable pre-natal investment choices $\left(C_{0}\right)$ and on maternal and child characteristics $(X)$.

$$
\left(\begin{array}{c}
W \\
A
\end{array}\right)=\left(\begin{array}{c}
\pi_{0}^{W} \\
\pi_{0}^{A}
\end{array}\right)+\left(\begin{array}{c}
\pi_{1}^{W} \\
\pi_{1}^{A}
\end{array}\right) C_{0}+\left(\begin{array}{c}
\pi_{2}^{W} \\
\pi_{2}^{A}
\end{array}\right) X+\left(\begin{array}{c}
\phi_{W} \\
\phi_{A}
\end{array}\right)
$$

Given our strategy, we limit the analysis to variables that are available in both the IHDP and ECLS-B. $C_{0}$ includes average number of cigarettes smoked per day during pregnancy, average number of alcoholic drinks consumed per week during pregnancy, an indicator of drug use, maternal weight gain during pregnancy, trimester of first pre-natal care and an indicator if no prenatal care services were used. The measures of $X$ are ethnicity, marital status, mother's schooling and age at child's birth, mother's parity, indicator for non-singleton pregnancy and indicator for female baby. Table 4 provides summary statistics from the ECLS-B and IHDP samples on these variables. Estimating the SUR model in the ECLS-B produces estimates for $\left(\pi_{0}^{W}, \pi_{1}^{W}, \pi_{2}^{W}, \pi_{0}^{A}, \pi_{1}^{A}, \pi_{2}^{A}\right)$, which are available in Table 5 .

Using the coefficients estimated through the SUR model, we generate a vector of estimates, for each observation in the ECLS-B and each birth outcome: $\left\{\hat{\pi}_{1}^{k} C_{0} ; \hat{\pi}_{0}^{k}+\hat{\pi}_{2}^{k} X ; \hat{\phi}_{k}\right\}_{k=W, A}$. The first term, $\hat{\pi}_{1}^{k} C_{0}$, measures the pre-natal investment level chosen by the mother, in units of the corresponding dependent variable (kilograms if $k=\mathrm{W}$, or weeks if $k=A$ ). The second term, $\hat{\pi}_{0}^{k}+\hat{\pi}_{2}^{k} X$, captures the predicted birth outcome associated with a particular maternal type $(X)$, holding pre-natal investment choices fixed. The third term corresponds to the residual, $\hat{\phi}_{k}=$ $k-\hat{\pi}_{1}^{k} C_{0}-\hat{\pi}_{0}^{k}-\hat{\pi}_{2}^{k} X$, which we will use as a noisy measure of the child's endowment. ${ }^{10}$

The distribution of $\hat{\pi}_{1}^{k} C_{0}$ in the ECLS-B is nationally representative. It measures the distribution of pre-natal investments that affect birth outcomes comparing among mothers of the same type $(X)$. We have two distributions, each one based on a different birth outcome $\left(\hat{\pi}_{1}^{W} C_{0}\right.$ and $\left.\hat{\pi}_{1}^{A} C_{0}\right)$. We record the percentiles of each distribution, its mean and standard deviation, and transform each individual's measure to a z-score. Next, we average the z-scores of pre-natal investment

\footnotetext{
${ }^{10}$ We do not use the second term elsewhere. It provides a different characterization of maternal type that summarized many demographic and family characteristics according to the roles in birth-condition determination. We prefer to focus on potential wage, which does a similar thing but in a way more directly relevant to postnatal economic choices.
} 
levels for each individual across birth weight and gestational age. We standardize the new average so that it has mean 0 and standard deviation $1 .{ }^{11}$ This is our final proxy for pre-natal investment, $I_{0}^{*}$. The distribution of $I_{0}^{*}$ in the ECLS-B is available in panel a of Figure 1. In addition, we use the same scoring procedure for each member of the IHDP sample. This delivers a measures of $I_{0}^{*}$ in the IHDP, which is measured with respect to the national norm. The result can be observed in panel $\mathrm{b}$ of Figure 1. Note that the distribution of pre-natal investment among IHDP mothers is slightly shifted to the left, when compared to the ECLS-B distribution.

Finally, we follow a similar procedure to create a measure of the child's endowment. We average the standardized birth weight and gestational age residuals within the ECLS-B $\left(\widehat{\phi}_{W}\right.$ and $\hat{\phi}_{A}$ ). We standardized this new average again to create a nationally representative distribution of endowments (Panel c in Figure 1). We then use the same scoring steps with the IHDP sample. The result is our proxy for $\phi$ and its distribution can be seen in panel $d$ of Figure 1. Note the strong difference in the endowment distribution of IHDP participants and the national distribution: children selected into the IHDP had very negative endowment shocks.

In general, children in the IHDP received strongly negative endowment shocks when compared to the distribution of shocks in the nationally representative ECLS-B sample. ${ }^{12}$ The IHDP sample's average percentile of child endowment is the $5^{\text {th }}$ percentile. The median percentile is the $3^{\text {rd }}$ and the average $\mathrm{z}$-score is -2.4 . Mothers in the IHDP tend to make lower levels of prenatal investment than observationally similar mothers in the national population. The average pre-natal investment percentile is the $27^{\text {th }}$ percentile. The median percentile is 19 and the average $\mathrm{z}$-score is $-\mathbf{0 . 8 5}$. The main factor driving selection into the IHDP sample appears to be extreme negative realizations of children's endowments rather than low levels of prenatal investment.

\subsection{Measures of postnatal choices}

We will look at heterogeneous IHDP-treatment effects on a variety of outcomes that reflect post-natal choices. These include both child-development outcomes and parental choices about

\footnotetext{
${ }^{11}$ This ensures the two outcomes receive equal weight, even though they are measured in different units.

${ }^{12}$ Appendix 10.2 contains details about how these variables are measured.
} 
allocation of time and money on inputs that affect child development and other uses. This section introduces the measures of these outcomes.

Table 6 presents summary statistics for all the variables in the main analysis. The primary outcome is child cognitive skill $(h)$ at the end of the intervention as measured by Stanford Binet IQ at 36 months (all ages are chronologically corrected, based on due date). Average IQ in the sample (88.4) is almost a standard deviation (15) below the national norm (100).

Inputs into the production function should reflect maternal and non-maternal effective units of care during the first three years of life. Hours per week of maternal care $(r)$ correspond to the average of maternal self-reported hours in the 18-month and 30-month family interviews. Hours of care at the CDCs $(t)$ come from administrative data and are the average weekly attendance over the 2 years it was offered. Hours of care with other care takers is calculated as a residual, using the child's time constraint $\left(n=T_{c}-r-t\right) .{ }^{13}$

We make a clear distinction between quantity $(r)$ and quality $\left(q^{r}\right)$ of maternal care. To measure quality, we use the Learning and Literacy component from the Infant-Toddler Home Environment score, which is assumed to be affected by maternal effort oriented towards building cognitive capacity in her child (Linver, Martin and Brooks-Gunn, 2004; Fuligni, Han and Brooks-Gunn, 2004). The IHDP gathered data for the Home Environment scores at $12-$ month and 36-months. Table 7 presents the yes-or-no questions available in the data. We created a quality index by performing factor analysis on the tetrachoric correlation matrix across items at each age. The values reported for $q^{r}$ in Table 6 correspond to the standardized quality index at 36 months. So, the units of $q^{r}$ are standard deviations within the IHDP sample.

We do not directly observe the quality of nonmaternal care $\left(q^{n}\right)$ in the IHDP. To measure it, we combine IHDP data on child and family characteristics and on the chosen nonmaternal care settings -- partner, sibling, grandmother, another relative, babysitter, day care home, day care center, someone else and the child's father, if he lives in another home - with data from the National Institute of Child Health and Human Development's Study of Early Child Care and

\footnotetext{
${ }^{13}$ We suppose $T_{C}=87.5$ hours per week. Based on Inglowstein, et al. (2003), p. 304, average night time sleep duration for 2 year olds is approximately 11.5 hours. Therefore, the average child would require $(24-11.5) \times 7$ hours of direct care per week.
} 
Youth Development (SECCYD) on similar variables and care quality. We use models of nonmaternal care quality estimated in the SECCYD based on these predictors and then score the IHDP sample using the SECCYD-derived estimates to proxy for $q^{n}$. We calibrate the hourly price of nonmaternal care $(\pi)$ and the scale of $q^{n}$ using contemporaneous survey data on prices (Kisker, Hofferth, Phillips, \& Farquar, 1991). Details are in Appendix 2.

\section{Results}

Participants in the IHDP were randomly assigned either to the treatment- or control-group. As a consequence, we can study the heterogeneity in reduced-form treatment effects using a standard regression framework. We present main results in tables 8 and 9. These tables explore the shortterm and long-term treatment effects of the IHDP intervention on cognitive development (Table 8 ), as well as the effect on all the inputs up to age 36 months which determine cognitive development (Table 9). In order to capture treatment heterogeneity, we split the sample using thresholds of potential wage and prenatal investment. We define low-wage (high-wage) mothers as those with a potential wage below (above) the $33^{\text {rd }}$ percentile of the distribution within the sample and capture this in an indicator variable. In a similar way, mothers whose level of prenatal investment is below (above) the sample's $33^{\text {rd }}$ percentile belong to the low (high) prenatal investment category. In these analyses, we also control for main effects of child endowment and site.

To explore robustness to this functional form assumption, we allow a different characterization of the relationships. We consider four dimensions of possible heterogeneity: child birthweight, mother's expected potential wage $(\widehat{w})$, pre-natal investment levels that affect the child's condition at birth $\left(I_{0}^{*}\right)$ estimated after conditionally controlling for many observable characteristics of the family, mother and pregnancy, and, lastly, the child's endowment $(\phi)$, which measures how that child's condition at birth in the national distribution of children from observably-similar families who made observably-similar prenatal investment choices. For each of four dimensions of possible heterogeneity $(x)$, we estimate a separate regression:

$$
y=\beta_{0}+\beta_{1} T+\beta_{2} x+\beta_{3} T x+\beta_{4} x^{2}+\beta_{5} T x^{2}+\delta \mathbb{I}[\text { site }]+\varepsilon
$$


where $y$ represents an outcome of interest, $T$ is an IHDP-treatment indicator, $x$ is the variable along which we want to measure differences in the treatment effect, and $\delta$ controls for site. Interaction with a quadratic of $x$ allows treatment effects to vary non-linearly with $x$. The treatment effect, as a function of $x$, is equal to:

$$
E[y \mid x, T=1]-E[y \mid x, T=0]=\beta_{1}+\beta_{3} x+\beta_{5} x^{2}
$$

The prior literature has found substantial differences in the IHDP's treatment effect across birth weights, usually with smaller effects at lower birth weights. However, as noted earlier, differences in birth weight reflect a combination in differences in family type, prenatal investment choices that may be reflect differences in parental preferences, and differences in other factors. The present study aims to unpack the heterogeneous effects by birth weight. To communicate the results clearly, we plot the estimated treatment effect and 95 percent confidence intervals at different values of the four dimensions of heterogeneity. Results are summarized in figures 2 through 10. Each figure corresponds to an outcome and its four panels plot the treatment effect across different values of birth weight, potential wage, pre-natal investment, and child endowment. ${ }^{14}$

\section{Cognitive and behavioral outcomes}

We begin by unpacking the known result that treatment effects on 36-month IQ were larger for children born weighing 2,000 - 2,500 grams (high low birth weight) than those born at lower weight (low low birth weight). Figure 2 plots the predicted IQ level for each birthweight and treatment group based on the empirical model above along with 95 percent confidence intervals. In the control-group, predicted IQ increases in birthweight up to about 1,500 grams and flattens out across higher weights. In contrast, in the treatment-group, predicted IQ starts off a bit flat and then increases with birthweight across the whole range above 1,000 grams.

This generates the result that treatment effect increases in birthweight. The first panel of Figure 3 displays the estimated treatment effect by birthweight along with 95 percent confidence intervals. There is strong evidence of a positive effect on IQ at 36 months, especially for those

\footnotetext{
${ }^{14}$ Each of the regressions is separate. For instance, we do not control for the endowment when estimating the treatment effects by mother's potential wage. This current structure seems to provide the most transparent interpretation.
} 
born at weights above 1,500 g. For children born lighter, there is more variance in outcomes and the estimated treatment effect is positive but estimates are noisier

In the second panel of Figure 2, we see that potential wage is a strong predictor of child IQ in both the treatment and control groups. However, the treatment boosts IQ for children of lowwage, but not high-wage, mothers (second panel of Figure 3). Among children of mothers with low- and mid-levels of potential wage, the treatment effect is large and precisely estimated. They gained around two-thirds of a standard deviation (10 points) of IQ. At higher levels of potential wage, the effect diminishes and becomes null.

These conclusions are consistent with the regression results presented in Table 8. Each column represents a different outcome: nationally-normed standardized IQ at various ages. For each outcome, the same specification is used. This specification is designed to test for heterogeneity in treatment effects by potential wage and prenatal investment level. Column 1 explores the effects on IQ at 36 months. The 0.733 (s.e. 0.0897) estimated effect of the treatment indicator measures the average treatment effect in the omitted category: children of mothers with low potential wage and low levels of prenatal investment. The 0.528 (s.e. 0.130) estimated coefficient on the indicator of higher-potential wage picks up the average difference between children of low- and higher-potential wage mothers in the control group. In a sense, this measures the socioeconomic status (SES)-based gap in cognitive skill. Echoing Duncan \& Sojourner (2013)'s finding based on family income, the treatment more than closed the SES gap at age- $3 .{ }^{15}$ The -0.265 (s.e. 0.126 ) estimated coefficient on the interaction between treatment and the higher-potential-wage indicator expresses the fact that the treatment impact was larger among children whose families faced tighter economic constraints (less impactful among children whose mothers had higher earning power). The 0.268 (s.e. 0.0605 ) estimated coefficient on the higher-prenatal-investment indicator has a sensible sign and strong effect. In the control-group, those who received higher levels of prenatal investment scored about a quarter of a standard deviation higher on IQ than those who received low levels of prenatal investment. This could be due to both prenatal investment and correlated postnatal investments. The $0.0801(0.0989)$ estimated coefficient on the interaction between treatment and the indicator of higher prenatal investment suggests that there was not significant heterogeneity in

${ }^{15}$ Duncan \& Sojourner excluded children born low, low-birth weight. This analysis does not. 
this dimension. The main effect of endowment percentile is not significant. Site dummies are included but not reported.

The remaining three columns capture the long-term effects on cognitive development at 5,8 and 18 years of age. Potential wage is a strong predictor of IQ at every age. On average, children of mothers whose potential wage is above the $33^{\text {rd }}$ percentile have an IQ which is 0.4 to 0.8 s.d. higher than the IQ of children in the low potential-wage group in the control group. In addition, the treatment effect fades down as children age. Most importantly, through age- 8 , the treatment effect is about 0.3 s.d. lower among children whose mothers have higher potential wages than among children whose mothers have low potential wages. This is evidence that the IHDP's treatment effects differ depending on mothers' potential wage, at least through age 8 . The interaction is not significant at age 18 although about a third of the sample has attrited then. ${ }^{16}$

Consider now prenatal investment. There is a strong and persistent gap in cognitive development, depending on how much parents invested during the prenatal period. We estimate there is a stable advantage of approximately a third of a standard deviation on IQ if parents' prenatal investment decisions locate them above the $33^{\text {rd }}$ percentile of the within sample distribution. This gap is found at every age, even at 18 years old. Finally, we found no heterogeneity on treatment effect between low- and high-levels of prenatal investment.

Return now to Figures 2 and 3. The graphs are consistent with the regressions results: the treatment group's predicted IQ is higher across the range of prenatal investment levels (panel three in Figure 2), but the estimated treatment effect is relatively constant across this range, with weak evidence of a small decline at high levels of prenatal investment (panel three in Figure 3). The fourth panel shows little relationship between the residual determinants of birth weight, that is child endowment, and the predicted IQ levels in either treatment group or the treatment effects.

\section{Time allocation}

Any effect of the IHDP treatment on child development cannot be interpreted simply as the effect of time spent at the high-quality centers available for families in the treatment group.

\footnotetext{
${ }^{16}$ Figures presenting heterogeneous treatment effects on IQ at each age allowing for quadratic interactions in each dimension are presented in Appendix Figures 1-3.
} 
Households react to the intervention by reallocating various resources, thus providing the child with a new combination of maternal and nonmaternal care inputs. For instance, any hour the child spends in a center is an hour the child does not spend in an alternative setting, such as in maternal care or market-based care. Any reduction in the hours of maternal care may provide relief that allows mothers to provide higher-quality of care in the (fewer) hours they provide care. The maternal hours freed up could be allocated to additional market labor or to other activities (called leisure here, but potentially including care of other children and a wide variety of alternative activities). This section describes evidence on reallocations in response to the IHDP's offer and how this response varies across different types of families.

Although children could use the services from the CDCs for up to 40 hours per week, average take-up in the treatment group was only about 16 hours. There were no substantial differences in take-up depending on child birthweight or prenatal investment level (Figure 4). Additional evidence of average take-up can be found on the first column of Table 9.

Heterogeneity by mother's potential wage reveals evidence of a non-monotone relationship. In the control group, no one could take up any hours. In the treatment group, mothers with the lowest and highest potential wages take up less hours than mothers with mid-range potential wages. Mothers with the lowest potential wages used about 15 hours per week of CDC care, those with wages of $\$ 10$ per hour used about 17 hours per week, and those with a $\$ 21$ potential wage used the CDC for just 7 hours per week.

Mothers who chose different levels of prenatal investment did not choose to take up significantly different amounts of CDC care. This is remarkable because it suggests that differences in maternal tastes did not drive differences in the take-up of the free service. The IHDP's offer of free transportation to and from the CDCs may have helped ensure that transportation-cost frictions did not create a channel for differences in maternal tastes to drive differences in CDC take up.

The strongest dimension of heterogeneity is that parents of children with lower endowments (born in worse-than-expected condition given their background and prenatal investment levels) took up significantly fewer CDC hours on average. Those in the lowest percentile of the national endowment distribution took up an average of 15 hours of CDC care per week, while 
those in the $40^{\text {th }}$ percentile of the national endowment distribution took up just over 20 hours (fourth panel in Figure 4). The first column of Table 9 also presents evidence of the positive correlation between the child's endowment and the average number of hours the child spent at the CDC.

As reflected by the child's time constraint, use of the CDC must substitute for either maternal care or other non-maternal care. To explore these patterns of substitution, consider figure 5, figure 6 and the second and third columns from Table 9. Figure 5 measures the treatment effect on hours of non-CDC, non-maternal care $(n)$; figure 6 does the same for hours of maternal care $(r)$. The opportunity cost of mother's time appears to be a fundamental driver in both cases, because the kinds of care that CDC hours substitute for varies substantially by maternal potential wage. First, consider the reaction of mothers with the highest potential wages. The treatment induced them to reduce the number of hours of other sources of non-maternal care by almost 17 hours per week and produced a barely significant effect on the number of hours of maternal care. Mothers with high potential wages tended to use the nonmaternal CDC services as a substitute for other non-maternal care sources rather than as a substitute for maternal care time. Mothers with low potential wages followed the opposite pattern of substitution. Treatment led them to reduce maternal-care time by 11 hours per week on average while reducing the number of hours of non-maternal care by only a small amount (approximately 5 hours per week). This substitution pattern can also be found on columns 2 and 3 of Table 9. Note the negative treatment effect of the IHDP intervention on hours of non-maternal care (4.7 hours per week) and hours of maternal care (11.9 hours per week) representing the effects in the low potential-wage, low prenatal investment omitted group. However, the negative treatment effect on hours of non-maternal care is even larger for those mother's whose potential wage is above the $33^{\text {rd }}$ percentile. In contrast, the negative treatment effect on maternal care time is larger for the opposite group, mothers whose opportunity cost of time is below the $33^{\text {rd }}$ percentile of the sample distribution.

Recall that parents of children with lower endowments took up about 5 hours less CDC care weekly on average. This largely crowded out other forms of nonmaternal care and did not reduce maternal-care hours. Finally, no heterogeneity by prenatal investment levels is evident. 
In conclusion, the allocation of child time among different caregivers, which is a key input into the production function of early skills, depends not just on the number of hours of free service available to all participants but also on the larger choice environment facing the household. The opportunity cost of mother's time is at the core of those decisions.

As reflected in the maternal time budget, any time the child spends in CDC care makes more non-parenting (of that child) time available, which must be divided between hours working for wages in the labor market $(L)$ or allocation of time to leisure $(l) .{ }^{17}$ Mothers of the lower birth weight children increased their labor-market hours but we do not see significant heterogeneity in treatment effects across different levels pre-natal investment. However, mothers with a very high potential wage reduced their number of work hours as a consequence of participating in the IHDP intervention (Figure 7 and fourth column in Table 9).

The allocation of hours to leisure differed considerably across households. Treatment-group mothers gained back some leisure time, except for parents of very low birth weight infants (birth weight of less than 1 kilogram), who increased their labor-market hours. The treatment effect on leisure appears somewhat strongest among low-wage mothers and, weakly, among those who had chosen lower level of prenatal investment (Figure 8). However, this does not show up as statistically significant in the regressions where neither interaction term is significant (fifth column in Table 9).

\section{Quality of maternal and non-maternal care}

Care time is not the only input in the production of early skills; the quality of care also matters. In our framework, mothers can choose the quality of the care they provide, through a combination of their own human capital and an effort choice. Therefore, we expect maternal effort to be sensitive to participation in the IHDP. Figure 9 presents the treatment effect on our preferred proxy for the quality of maternal care. It corresponds to the components of the HOME score, at 36 months, which are related to the promotion of learning and literacy (Linver, Martin

\footnotetext{
${ }^{17}$ We define "leisure" as a very broad, residual category: it corresponds to any time the mother has left after accounting for time caring for her IHDP-study child $(r)$ and working in the labor market $(L)$. So it includes time spent caring exclusively for any other children, for elders, volunteering, engaged in home production, as well as activities more conventionally considered as leisure such as reading or sleeping.
} 
and Brooks-Gunn, 2004; Fuligni, Han and Brooks-Gunn, 2004). The sixth column of Table 9 presents the related regression results.

The pattern of results is interesting and important. Our proxy for the quality of maternal care is positively correlated with mothers' potential wage and prenatal investments. Among mothers with low potential wages, the treatment increases the proxy measure of maternal-care quality but the effect decreases with mother's potential wage. According to the regression results, the treatment effect on the quality of maternal care is 0.53 s.d. for households who belong to the bottom third of the potential wage and prenatal investment distributions. The size of the treatment effect is cut in half among households with higher potential wage (sixth column in Table 9).

This pattern of effects on the quality of maternal care is the mirror image of that observed on the quantity of maternal care. For mothers with high potential wages, there is no treatment effect on either maternal-care quantity or quality. In contrast, for mothers with low potential wages, there is a substantial negative effect on maternal-care quantity and a substantial positive effect on maternal-care quality.

Our economic model offers a possible reason why this might be. The model supposes that, for a given person in a given moment, parenting better requires more effort. Also, for a person providing a given level of parenting quality, parenting longer requires more effort. The treatment allowed mothers with low potential wages to reduce the number of hours they provided direct care to the child, while still feeling comfortable that the child would receive high-quality care. Absent the intervention, they could not afford much high-quality, marketbased care. Access to this high-quality care environment reduced the number of hours of parenting they did, providing some effort relief for the mothers. This relief created space for them to raise their instantaneous effort levels during the shorter time they provided care, generating higher observed quality of maternal care. This was not the case among high-wage mothers. This drastic difference in the treatment effect on the quality of maternal care could be one of the main reasons behind the heterogeneous treatment effect on cognitive development. We also observe decreasing treatment effects on maternal-care quality by prenatal investment level and by child endowment. 
Figure 10 presents heterogeneous treatment effects on the quality of nonmaternal, non-CDC care used. The effects are null among mothers with low potential wages and turns slightly negative as wages rise, in the subpopulation where the quantity of such hours declines dramatically (panel 2). A qualitatively similar pattern appears for prenatal investment level in panel 3. Those who chose low levels of prenatal investment do not change their average nonmaternal care quality, though recall that they do reduce quantity. However, those with high levels of prenatal investment reduce the quality of nonmaternal care they chose, along with the quantity of such care. Such pattern of results is consistent with the last column of Table 9.

This kind of effect may be driven by substitution between CDC care and market-based, nonmaternal care. As we posit in our model, CDC care may be a perfect substitute for highquality market based care. It is possible that someone could offer such a service in the market. Therefore, when families that would otherwise spend a lot of financial resources on high-quality nonmaternal care are offered the chance to get it for free, they do so and they cut back on their financial expenditures on its substitutes.

\section{Limitations}

Our discussion ignores other components of the IHDP treatment beyond the CDCs, such as the offer of weekly home visiting during the child's first year of life. In the literature and in our own work, there is little evidence of treatment effects at age 12 months. Appendix Table 3 uses a parallel structure to Tables 8 and 9 to assess whether treatment had differential effects on child mental development or on the quality of maternal care at age 12 months, after a year of weekly home visits are offered but before the offer of free CDC care starts. There are no main effects of treatment on either variable and no significant interaction effects. However, as discussed above, after access to the CDC started, large effects became evident. That said, we cannot rule out the possibility that a program that omitted this element of the IHDP treatment would have different effects than those observed.

The sample is composed exclusively of children born low birth weight and premature. Some may have suffered developmental compromise and may be subject to different developmental processes than children born under normal conditions. There are a few points to make regarding this issue. First, we characterize the sample with respect to the criteria on which they are 
selected (birth weight and gestational age at birth) within the context of a nationallyrepresentative birth cohort and with respect to the determinants of these selection variables (maternal characteristics, pre-natal investment choices, and child endowment) and we build these differences into our model. Second, even if one is reluctant to generalize outside the sample's support, the estimates are valuable as informative about children born low birth weight and premature. Third, there is no evidence of a break in the relationship between birth weight and cognitive skills at 2,500 grams (Figlio, Guryan, Karbownik, \& Roth, 2014).

We ignore the costs of goods as inputs, aside from measuring the quality of care. We believe this is justified at this very early stage of development, although the cost of goods themselves and their ability to substitute for or complement personal care-giver attention may be more important as children age (Del Boca, Flinn, \& Wiswall, 2014).

Our analyses produce unbiased estimates under the assumption that data are missing completely at random. However, this may not be a valid assumption. Future work will assess robustness to alternative assumptions about missing data.

\section{Conclusion}

Each child has only one first 3 years. The quality of the environments they encounter in this "first 1,000 days" has long-term consequences. Policies that seek to improve these environments must be designed in a way that respects parents' values and constructively loosens the constraints that parents face. The impacts of policies will be determined by the way the distribution of responses that parents choose.

The quality, quantity, and price of the subsidized environment offered are key design variables. Different parents will react to the same offer in different ways partially because they have different alternatives available. The offer of free, high quality care has large positive effect on the cognitive development of children of mothers with lower potential wages. For these children, access to the CDC triggered increases in hours spent in high-quality nonmaternal care and reductions in maternal-care time while also triggering an increase in the quality of maternal care. In contrast, the effect on children of higher potential wage mothers are different. They take up about the same amount of CDC hours but this crowds out nonmaternal, rather than maternal care, and yields smaller impacts on child skill. This result - differential effects by maternal 
earning power - echoes earlier findings (Bernal \& Keane, 2010; Duncan \& Sojourner, 2013) but the current paper adds new evidence on mechanisms.

Gelber \& Isen (2013) found that parents with kids randomly selected for Head Start eligibility raise the level of parenting quality. They interpret this as evidence of perceived complementarity between parental and non-parental care quality. However, they also recognize that this could be due instead to "changes in parent time with children through impacts on the parents' time constraint" but lack good measures of parental care quantity to get at this directly. We reproduce their main empirical finding, that low-income parents whose children are eligible for free child care do increase their parenting quality, but we extend the analysis to incorporate a measure of maternal care quantity. We find a decline in maternal care hours for these families. Further, we find that treatment does not reduce maternal care hours or increase parenting quality among higher potential-wage families. This evidence is consistent with our theory that parenting effort matters and that providing access to high-quality nonmaternal care can reduce maternal stress and create the psychic space for parents to parent better.

Intervention programs like the IHDP and some policies, such as Early Head Start and Child Care Assistance Block Grant funding, subsidize child access to nonparental care during this critical developmental period although quality levels tend to be lower than that provided in the IHDP CDCs. Given this offer, parents may take up free, low-quality care over costly, higherquality care that they would have provided or purchased themselves (Peltzman, 1973). This could produce negative effects on child skill, though it may increase family income. Future work will estimate a structural model of parents' responses to the IHDP offer and use this as a way of predicting the impacts of child care subsidies with alternative, counter-factual designs, that is alternative combinations of nonparental care quality, quantity, and price. 


\section{Works Cited}

Aizer, A., \& Cunha, F. (2012). The Production of Human Capital: Endowments, Investments, and Fertility. Cambridge, Mass.: National Bureau of Economic Research.

Almond, D., \& Mazumder, B. (2013). Fetal Origins and Parental Responses. Chicago, Ill.: Federal Reserve Bank of Chicago.

Berlin, L. J., Brooks-Gunn, J., \& McCarton, C. (1998). The Effectiveness of Early Intervention: Examining Risk Factors and Pathways to Enhanced Development. Preventative Medicine, 27, 238-245.

Bernal, R., \& Keane, M. P. (2010). Quasi-structural estimation of a model of childcare choices and child cognitive ability production. Journal of Econometrics, 156(1), 164-189.

Bernal, R., \& Keane, M. P. (2011). Child Care Choices and Children's Cognitive Achievement: The Case of Single Mothers. Journal of Labor Economics, 29(3), 459-512.

Bradley, R. H., Burchinal, M. R., \& Casey, P. H. (2010). Early Intervention: The Moderating Role of the Home Environment. Applied Developmental Science, 5(1), 2-8.

Bradley, R. H., Whiteside, L., Mundfrom, D. J., Casey, P. H., Caldwell, B. M., \& Barrett, K. (1994). Impact of the Infant Health and Development Program (IHDP) on the Home Environments of Infants Born Prematurely and with Low Birthweight. Journal of Educational Psychology, 86(4), 531-541.

Brooks-Gunn, J., Gross, R. T., Kraemer, H. C., Spiker, D., \& Shapiro, S. (1992). Enhancing the Cognitive Outcomes of Low Birth Weight, Premature Infants: For Whom Is the Intervention Most Effective? Pediatrics, 89(6), 1209-1215.

Brooks-Gunn, J., Klebanov, P. K., Liaw, F.-r., \& Spiker, D. (1993). Enhancing the Development of Low-Birthweight, Premature Infants: Changes in Cognition and Behavior over the First Three Years. Child Development, 64(3), 736-753.

Brooks-Gunn, J., McCormick, M. C., Shapiro, S., Benasich, A. A., \& Black, G. W. (1994). The Effects of Early Education on Maternal Employment, Public Assistance, and Health Insurance: The Infant Health and Development Program. American Journal of Public Health, 84(6), 924-931.

Cameron, A. C., \& Trivedi, P. K. (2010). Microeconometrics Using Stata. Stata Press.

Card, D., DellaVigna, S., \& Malimendier, U. (2011). The Role of Theory in Field Experiments. Journal of Economic Perspectives, 25(3), 29-62.

Cascio, E., \& Whitmore Schanzenbach, D. (2013). The Impacts of Expanding Access to HighQuality Preschool Education. Washington, D.C.: Brookings Institution. 
Committee on Integrating the Science of Early Childhood Development . (2000). From Neurons to Neighborhoods: The Science of Early Childhood Development. (D. A. Phillips, \& J. P. Shonkoff, Eds.) Washington, D.C.: National Academy Press.

Cunha, F., \& Heckman, J. J. (2007). The technolgy of skill formation. American Economic Review, 97(2), 31-47.

Cunha, F., Heckman, J. J., \& Schennach, S. M. (2010). Estimating the Technology of Cognitive and Noncognitive Skill Formation. Econometrica, 78(3), 883-931.

Cunha, F., Heckman, J. J., Lochner, L., \& Masterov, D. V. (2006). Interpreting the evidence on life cycle skill formation. In E. Hanushek, \& F. Welch, Handbook of Economics of Education (Vol. 1, pp. 697-812). Boston, Mass.: Elsevier.

Currie, J., \& Almond, D. (2011). Human Capital Development before Age Five. In D. Card, \& O. Ashenfelter, Handbook of Labor Economics (Vol. 4b, pp. 1315-1486). Elsevier.

Del Boca, D., Flinn, C., \& Wiswall, M. (2014). Household Choices and Child Development. Review of Economic Studies, 81(1), 137-185.

Del Bono, E., Ermisch, J., \& Francesconi, M. (2012). Intrafamily Resource Allocations: A Dynamic Structural Model of Birth Weight. Journal of Labor Economics, 30(3), 657706.

Duncan, G. J., \& Magnuson, K. (2013). Investing in preschool programs. Journal of Economic Perspectives, 27(2), 109-132.

Duncan, G., \& Sojourner, A. (2013). Can Intensive Early Childhood Intervention Programs Eliminate Income-based Cognitive and Achievement Gaps? Journal of Human Resources, 48(4), 945-968.

Figlio, D., Guryan, J., Karbownik, K., \& Roth, J. (2014). The Effects of Poor Neonatal Health on Children's Cognitive Development. American Economic Review, 104(12), 39213955.

Flood, S., King, M., Ruggles, S., \& Warren, J. W. (2015). Integrated Public Use Microdata Series, Current Population Survey: Version 4.0. [Machine-readable database]. Minneapolis.

Gelber, A., \& Isen, A. (2013). Children's Schooling and Parents' Behavior: Evidence from the Head Start Impact Study. Journal of Public Economics, 101, 25-38.

Gormley, W., Phillips, D., \& Gayer, T. (2008). Preschool Programs Can Boost School Readiness. Science, 320(5884), 1723-24. 
Gross, R. T., Spiker, D., \& Haynes, C. W. (1997). Helping low birth weight, premature babies : the infant health and development program. Stanford, Calif.: Stanford University Press.

Hanson, J. L., Hair, N., Shen, D. G., Shi, F., Gilmore, J. H., Wolfe, B. L., \& Pollak, S. D. (2013). Family Poverty Affects the Rate of Human Infant Brain Growth. PLoS one, $8(12)$.

Heckman, J. J. (1974). Shadow Prices, Market Wages, and Labor Supply. Econometrica, 42(4), 679-694.

Heckman, J. J. (2006). Skill Formation and the Economics of Investing in Disadvantaged Children. Science, 312(1900), 1900-1902. doi:10.1126/science.1128898

Heckman, J. J. (2007). The economics, technology, and neuroscience of human capability formation. PNAS, 104(33), 13250-13255.

Heckman, J. J., \& Pinto, R. (2013). Econometric Mediation Analyses: Identifying the Sources of Treatment Effects from Experimentally Estimated Production Technologies with Unmeasured and Mismeasured Inputs. Cambridge, Mass.: National Bureau of Economic Research.

Kimmel, J., \& Connelly, R. (2006). Mothers' Time Choices: Caregiving, Leisure, Home Production, and Paid Work. Journal of Human Resources, 644-681.

Kisker, E. E., Hofferth, S. L., Phillips, D. A., \& Farquar, E. (1991). A Profile of Child Care Settings: Early Education and Care in 1990. Princeton, N.J.: Mathematica Policy Research.

Knudsen, E. I., Heckman, J. J., Cameron, J. L., \& Shonkoff, J. P. (2006). Economic, neurobiological, and behavioral perspectives on building America's future workforce. Proceedings of the National Academy of Sciences, 103(27), 10144-10162.

Lee, V. E., \& Burkam, D. T. (2002). Inequality at the starting gate: Social background differences in achievement as children begin school. Washington, D.C.: Economic Policy Institute.

Mulligan, C. B., \& Rubinstein, Y. (2008). Selection, Investment, and Women's Relative Wages Over Time. Quarterly Journal of Economics, 123(3), 1061-1110.

Nord, C., Edwards, B., Andreassen, C., Green, J. L., \& Wallner-Allen, K. (2006). Early Childhood Longitudinal Study, Birth Cohort (ECLS-B), user's manual for the ECLS-B longitudinal 9-month-2-year data file and electronic codebook (NCES 2006-046).

Olds, D. L., Kitzman, H., Cole, R., Robinson, J., Sidora, K., Luckey, D. W., . . Holmberg, J. (2004). Effects of Nurse Home-Visiting on Maternal Life Course and Child 
Development: Age 6 Follow-Up Results of a Randomized Trial. Pediatrics, 114(6), 1550-1559.

Peltzman, S. (1973). The Effect of Government Subsidies-in-Kind on Private Expenditures: The Case of Higher Education. Journal of Political Economy, 81(1), 1-27.

Ramey, C. T., Campbell, F. A., \& Ramey, S. L. (1999). Early Intervention: Successful Pathways to Improving Intellectual Development. Developmental Neuropsychology, 16(3), 385-392.

Reardon, S. F. (2011). The Widening Academic Achievement Gap Between the Rich and the Poor: New Evidence and Possible Explanations. In G. J. Duncan, \& R. J. Murnane, Whither Opportunity (pp. 91-116). New York, N.Y.: Russell Sage Foundation.

Ribar, D. C. (1995). A Structural Model of Child Care and the Labor Supply of Married Women. Journal of Labor Economics, 13(3), 558-597.

Sapolsky, R. M. (2004). Social Status and Health in Humans and Other Animals. Annual Review of Anthropology, 33, 393-418. doi:10.1146/annurev.anthro.33.070203.144000 


\section{Tables}

Table 1 - Possible caretakers and effective units of care provided

\begin{tabular}{|l|l|c|c|c|}
\hline & Caretaker & \multicolumn{3}{|c|}{ Variables in the model } \\
\hline \multirow{2}{*}{ Maternal Care } & Mother & $\begin{array}{c}\text { Time with } \\
\text { caretaker }\end{array}$ & $\begin{array}{c}\text { Quality of } \\
\text { care }\end{array}$ & $\begin{array}{c}\text { Effective units } \\
\text { of care provided }\end{array}$ \\
\hline \multirow{2}{*}{ Non-maternal care } & Free Daycare (CDC) & $r$ & $q^{r}$ & $q^{r} r$ \\
\cline { 2 - 5 } & Non-maternal, non-CDC & $n$ & $q^{t}$ & $q^{t} t$ \\
\hline
\end{tabular}

Note: total effective units of non-maternal care will be equal to $\left(q^{t} t\right)+\left(q^{n} n\right)$. 
Table 2 - Summary statistics for variables in the potential wage model $(\widehat{w})$

\begin{tabular}{|c|c|c|c|c|c|c|c|}
\hline \multirow{2}{*}{\multicolumn{2}{|c|}{ Continuous variables }} & \multicolumn{3}{|c|}{ CPS } & \multicolumn{3}{|c|}{ IHDP } \\
\hline & & & & & & & \\
\hline \multirow{3}{*}{$\begin{array}{l}\text { Hourly Rate of } \\
\text { Pay } \\
\text { Log, US\$ of } \\
2012\end{array}$} & & Mean & $\begin{array}{l}\text { Std. } \\
\text { Dev. }\end{array}$ & $\mathrm{N}$ & Mean & $\begin{array}{l}\text { Std. } \\
\text { Dev. }\end{array}$ & $\mathrm{N}$ \\
\hline & $\begin{array}{l}\text { Working mothers } \\
\text { only }\end{array}$ & 2.60 & 0.56 & 18,680 & 2.09 & 0.71 & 542 \\
\hline & All the sam & & & & 1.89 & 0.83 & 985 \\
\hline \multirow{2}{*}{\multicolumn{2}{|c|}{ Potential experience (years) }} & 0.60 & 0.49 & 30,889 & 0.52 & 0.50 & 913 \\
\hline & & 9.61 & 5.60 & 30 & 6.49 & 5.28 & 985 \\
\hline \multirow{2}{*}{\multicolumn{2}{|c|}{$\begin{array}{r}\text { Number of own children under age } 5 \\
\text { Age of youngest own child in }\end{array}$}} & 1.30 & 0.53 & 30,889 & 1.50 & 0.71 & 985 \\
\hline & & & & & & & \\
\hline \multirow{2}{*}{\multicolumn{2}{|c|}{$\begin{array}{r}\text { household } \\
\text { Number of own children } 5 y \text { old or } \\
\text { older }\end{array}$}} & 1.75 & 1.39 & 30,889 & 1.70 & 0.68 & 985 \\
\hline & & 0.77 & 1.03 & 30,889 & 0.46 & 0.84 & 985 \\
\hline
\end{tabular}

\begin{tabular}{|c|c|c|c|c|}
\hline Maternal education & & & & \\
\hline & $\begin{array}{r}\text { Share } \\
(\%)\end{array}$ & $\mathrm{N}$ & $\begin{array}{r}\text { Share } \\
(\%)\end{array}$ & $\mathrm{N}$ \\
\hline Less than High School & 18.4 & 5,682 & 40.0 & 394 \\
\hline High School graduate & 43.7 & 13,505 & 27.4 & 270 \\
\hline Some College & 19.9 & 6,157 & 20.0 & 197 \\
\hline College graduate & 18.0 & 5,545 & 12.6 & 124 \\
\hline
\end{tabular}

\begin{tabular}{|c|c|c|c|c|}
\hline Race and Ethnicity & & & & \\
\hline & $\begin{array}{r}\text { Share } \\
(\%)\end{array}$ & $\mathrm{N}$ & $\begin{array}{r}\text { Share } \\
(\%)\end{array}$ & $\mathrm{N}$ \\
\hline Non-Hispanic White & 70.4 & 21,752 & 33.4 & 329 \\
\hline African American & 11.0 & 3,383 & 52.5 & 517 \\
\hline Hispanic & 14.6 & 4,513 & 10.7 & 105 \\
\hline Other & 4.0 & 1,241 & 3.5 & 34 \\
\hline
\end{tabular}

\begin{tabular}{|c|c|c|c|c|}
\hline \multirow{2}{*}{ Marital status } & & & & \\
\hline & $\begin{array}{r}\text { Share } \\
(\%)\end{array}$ & $\mathrm{N}$ & $\begin{array}{r}\text { Share } \\
(\%)\end{array}$ & $\mathrm{N}$ \\
\hline Married & 80.8 & 24,964 & 46.2 & 455 \\
\hline Single & 8.6 & 2,661 & 45.8 & 451 \\
\hline Separated / Divorced / Widowed & 10.6 & 3,264 & 8.0 & 79 \\
\hline
\end{tabular}

CPS Sample: IPUMS-CPS extract, Minnesota Population Center. 1986-89 March Samples. Women, age 15 to 55, with at least one child under the age of 5. Unpaid family workers and self-employed women not included. Hourly Rate of Pay is equal to the ratio of last year's total labor income divided by usual hours per week times weeks worked. Wages below $\$ 3.73$ and above $\$ 80$ in 2012 dollars are trimmed. IHDP: Infant Health and Development Program sample. Hourly Rate of Pay for the IHDP sample is the predicted value based on the Heckman selection model presented in Table 3. 
Table 3 - Estimates from Heckman selection model in CPS sample

\begin{tabular}{|c|c|c|}
\hline VARIABLES & $\begin{array}{c}(1) \\
\text { Ln(hourly wage) }\end{array}$ & $\begin{array}{c}(2) \\
1[\text { worked] }\end{array}$ \\
\hline Potential experience & $\begin{array}{c}0.0612 * * * \\
(0.0115)\end{array}$ & $\begin{array}{c}0.0648 * * * \\
(0.0233)\end{array}$ \\
\hline Potential experience, squared & $\begin{array}{l}-0.00150 \\
(0.00165)\end{array}$ & $\begin{array}{c}-0.00751^{* *} \\
(0.00327)\end{array}$ \\
\hline Potential experience, cubed & $\begin{array}{l}-3.10 \mathrm{e}-05 \\
(8.85 \mathrm{e}-05)\end{array}$ & $\begin{array}{l}0.000285^{*} \\
(0.000173)\end{array}$ \\
\hline Potential experience, $\wedge 4$ & $\begin{array}{l}1.09 \mathrm{e}-06 \\
(1.54 \mathrm{e}-06)\end{array}$ & $\begin{array}{l}-3.74 \mathrm{e}-06 \\
(2.96 \mathrm{e}-06)\end{array}$ \\
\hline Education: Less than High School & $\begin{array}{l}0.0981 * \\
(0.0541)\end{array}$ & $\begin{array}{c}-0.759 * * * \\
(0.0860)\end{array}$ \\
\hline Education: Some College & $\begin{array}{c}0.0700 \\
(0.0455)\end{array}$ & $\begin{array}{r}0.348 * * * \\
(0.0992)\end{array}$ \\
\hline Education: College degree & $\begin{array}{l}0.429 * * * \\
(0.0540)\end{array}$ & $\begin{array}{c}0.515^{* * *} \\
(0.130)\end{array}$ \\
\hline Experience * Less HS indicator & $\begin{array}{c}-0.0493^{* *} \\
(0.0198)\end{array}$ & $\begin{array}{l}0.0592 * \\
(0.0337)\end{array}$ \\
\hline Experience $*$ Some Coll. indicator & $\begin{array}{l}0.0532 * * \\
(0.0208)\end{array}$ & $\begin{array}{l}-0.0773 * \\
(0.0448)\end{array}$ \\
\hline Experience $*$ Coll. grad. indicator & $\begin{array}{c}0.0249 \\
(0.0253)\end{array}$ & $\begin{array}{l}-0.0662 \\
(0.0614)\end{array}$ \\
\hline Experience $2^{*}$ Less HS indicator & $\begin{array}{c}0.00265 \\
(0.00241)\end{array}$ & $\begin{array}{l}-0.00372 \\
(0.00424)\end{array}$ \\
\hline Experience $^{\wedge} 2 *$ Some Coll. indicator & $\begin{array}{l}-0.00748 * * \\
(0.00303)\end{array}$ & $\begin{array}{c}0.00916 \\
(0.00647)\end{array}$ \\
\hline Experience $2^{*}$ Coll. grad. indicator & $\begin{array}{l}-0.00423 \\
(0.00389)\end{array}$ & $\begin{array}{c}0.00521 \\
(0.00967)\end{array}$ \\
\hline Experience ${ }^{\wedge} *$ Less HS indicator & $\begin{array}{l}-4.75 e-05 \\
(0.000113)\end{array}$ & $\begin{array}{c}0.000113 \\
(0.000204)\end{array}$ \\
\hline Experience $^{\wedge} 3 *$ Some Coll. indicator & $\begin{array}{l}0.000374 * * \\
(0.000164)\end{array}$ & $\begin{array}{l}-0.000382 \\
(0.000352)\end{array}$ \\
\hline Experience $3^{*}$ Coll. grad. indicator & $\begin{array}{c}0.000228 \\
(0.000229)\end{array}$ & $\begin{array}{l}-0.000198 \\
(0.000593)\end{array}$ \\
\hline Experience $\wedge 4 *$ Less HS indicator & $\begin{array}{c}7.21 \mathrm{e}-09 \\
(1.79 \mathrm{e}-06)\end{array}$ & $\begin{array}{l}-8.05 \mathrm{e}-07 \\
(3.29 \mathrm{e}-06)\end{array}$ \\
\hline Experience $^{\wedge} 4 *$ Some Coll. indicator & $\begin{array}{c}-5.74 \mathrm{e}-06^{* *} \\
(2.88 \mathrm{e}-06)\end{array}$ & $\begin{array}{c}5.39 \mathrm{e}-06 \\
(6.26 \mathrm{e}-06)\end{array}$ \\
\hline Experience $\wedge 4 *$ Coll. grad. indicator & $\begin{array}{l}-4.47 \mathrm{e}-06 \\
(4.45 \mathrm{e}-06)\end{array}$ & $\begin{array}{c}3.90 \mathrm{e}-06 \\
(1.23 \mathrm{e}-05)\end{array}$ \\
\hline Race: African American & $\begin{array}{c}-0.0932 * * * \\
(0.0132)\end{array}$ & $\begin{array}{c}0.230 * * * \\
(0.0282)\end{array}$ \\
\hline Race: Hispanic & $\begin{array}{c}-0.0712 * * * \\
(0.0132)\end{array}$ & $\begin{array}{c}-0.0992 * * * \\
(0.0247)\end{array}$ \\
\hline
\end{tabular}


Race: Other

$\begin{array}{cc}-0.0418^{* *} & -0.0851 * * \\ (0.0199) & (0.0389) \\ -0.0403 * * & -0.183 * * \\ (0.0166) & (0.0930) \\ -0.0964 * * * & -0.173 * \\ (0.0123) & (0.0963) \\ & -0.373 * * * \\ & (0.0168) \\ & 0.00242 \\ & (0.00680) \\ & -0.156 * * \\ & (0.00936) \\ & -0.107 * \\ & (0.0566) \\ & 0.0996 * \\ & (0.0531) \\ & 0.0233 \\ & (0.0212) \\ & 0.0987 * * \\ & (0.0197) \\ & -0.0777 * * \\ & (0.0311) \\ & -0.0635 * * \\ 0.300 * * * & (0.0230) \\ (0.0283) & \\ (0.0331) & (0.0626)\end{array}$

Marital status: Single

Marital status: Sep./Div./Wid.

Number of own children under age 5 in hh

Age of youngest own child in household

$(0.00680)$

Number of own children 5 years old or older

$(0.00936)$

Num. of children $<5 *$ Single indicator

$0.107 *$

Num. of children $<5 *$ Sep./Div./Wid. indicator

Age youngest child * Single indicator

Age youngest child * Sep./Div./Wid. indicator

Num. of children $>=5 *$ Single indicator

Num. of children $>=5 *$ Sep./Div./Wid. indicator

Lambda

Observations

Note: the selection equation and the wage equation included as additional controls indicators for division (New England, Middle Atlantic, West North Central, South Atlantic, East South Central, West South Central, Mountain and Pacific) and metropolitan area (Boston, MA; Dallas-Forth Worth, TX; Little Rock-North Little Rock, AR; Miami-Hialeah, FL; New Haven-Meriden, CT; New York, NY; Philadelphia, $\mathrm{PA} / \mathrm{NJ}$; Seattle-Everett, WA). This additional control are not reported. 
Table 4 - Summary statistics for pre-natal investment model in the ECLS-B and IHDP samples

\begin{tabular}{|c|c|c|c|c|}
\hline & \multicolumn{2}{|c|}{ ECLS-B } & \multicolumn{2}{|c|}{ IHDP } \\
\hline & $\begin{array}{c}\text { Mean or } \\
\text { Percentage }\end{array}$ & Std. Dev. & $\begin{array}{c}\text { Mean or } \\
\text { Percentage }\end{array}$ & Std. Dev. \\
\hline \multicolumn{5}{|c|}{ Conditions at birth } \\
\hline Birth weight (kg) & 3.3 & 0.6 & 1.8 & 0.4 \\
\hline Gestational age (weeks) & 38.7 & 2.4 & 33.0 & 2.6 \\
\hline \multicolumn{5}{|c|}{ Pre-natal investment choices $\left(C_{0}\right)$} \\
\hline Maternal weight gain $(\mathrm{kg})$ & 34.9 & 21.9 & 23.5 & 13.0 \\
\hline Cigarettes per day & 1.1 & 4.0 & 4.3 & 7.9 \\
\hline Alcoholics drinks per week & 0.04 & 0.3 & 0.2 & 0.7 \\
\hline Used drugs $(\%)$ & $4.3 \%$ & - & $3.8 \%$ & - \\
\hline Trimester of first prenatal check-up & 1.2 & 0.5 & 1.3 & 0.6 \\
\hline No prenatal check-up & $0.9 \%$ & - & $4.5 \%$ & - \\
\hline \multicolumn{5}{|c|}{ Child characteristics $(X)$} \\
\hline Female & $49.0 \%$ & - & $50.8 \%$ & - \\
\hline Non-singleton fetus & $3.1 \%$ & - & $11.2 \%$ & - \\
\hline African American & $15.2 \%$ & - & $52.4 \%$ & - \\
\hline Hispanic & $20.3 \%$ & - & $10.6 \%$ & - \\
\hline Other ethnicity & $6.6 \%$ & - & $3.4 \%$ & - \\
\hline \multicolumn{5}{|c|}{ Mother characteristics $(X)$} \\
\hline Parity & 2.0 & 1.1 & 1.8 & 1.1 \\
\hline Never married & $25.8 \%$ & - & $45.7 \%$ & - \\
\hline Separated, divorced or widowed & $6.7 \%$ & - & $8.0 \%$ & - \\
\hline Age at birth (years) & 28.1 & 6.1 & 24.7 & 6.0 \\
\hline Less than High School & $17.6 \%$ & - & $40 \%$ & - \\
\hline Some College & $27.9 \%$ & - & $20 \%$ & - \\
\hline College graduate & $26.0 \%$ & - & $12.5 \%$ & - \\
\hline
\end{tabular}

ECLS-B: summary statistics based on full sample weights (w1r0). 
Table 5 - Estimates from SUR model for pre-natal investment using the ECLS-B sample

\begin{tabular}{|c|c|c|c|c|}
\hline \multirow[t]{3}{*}{ Dependent variable } & \multicolumn{2}{|c|}{ Birth weight $(W)$} & \multicolumn{2}{|c|}{ Gestational age $(A)$} \\
\hline & Coefficient & Std. Err. & Coefficient & Std. Err. \\
\hline & \multicolumn{2}{|c|}{$\pi_{1}^{W}$} & \multicolumn{2}{|c|}{$\pi_{1}^{A}$} \\
\hline Maternal weight gain $(\mathrm{kg})$ & 10.51 & .030 & .01 & .0001 \\
\hline Maternal weight gain $\wedge 2$ & -.04 & .0002 & -.0000917 & $8.93 \mathrm{e}-07$ \\
\hline Cigarettes per day & -12.89 & .078 & -.005 & .0003 \\
\hline Alcoholics drinks per week & -60.37 & 2.310 & .16 & .010 \\
\hline Alcoholics drinks per week ${ }^{\wedge} 2$ & -2.69 & .908 & -.08 & .004 \\
\hline Used drugs $(\%)$ & -12.67 & 1.505 & .13 & .006 \\
\hline Trimester of first prenatal check-up & -14.99 & .602 & .06 & .002 \\
\hline \multirow[t]{2}{*}{ No prenatal check-up } & -60.35 & 3.245 & -.08 & .014 \\
\hline & \multicolumn{2}{|c|}{$\pi_{2}^{W}$} & \multicolumn{2}{|c|}{$\pi_{2}^{A}$} \\
\hline Child: female & -106.34 & .602 & .08 & .002 \\
\hline Child: non-singleton fetus & -1112.95 & 1.742 & -3.59 & .007 \\
\hline Child: African American & -214.45 & .972 & -.43 & .004 \\
\hline Child: Hispanic & -58.80 & .839 & -.13 & .003 \\
\hline Child: Other ethnicity & -118.99 & 1.239 & -.19 & .005 \\
\hline Mother: Never married & -38.92 & .893 & -.10 & .003 \\
\hline $\begin{array}{r}\text { Mother: Separated, divorced or } \\
\text { widowed }\end{array}$ & -59.00 & 1.257 & -.009 & .005 \\
\hline Mother: age at birth (years) & 27.87 & .453 & .06 & .001 \\
\hline Mother: age at birth ${ }^{\wedge} 2$ & -.44 & .007 & -.001 & .0000334 \\
\hline Mother: Less than High School & -33.94 & .955 & .03 & .004 \\
\hline Mother: Some College & 33.44 & .834 & -.07 & .003 \\
\hline Mother: College graduate & 28.16 & .958 & -.01 & .004 \\
\hline Parity & 96.18 & .802 & -.04 & .003 \\
\hline \multirow[t]{2}{*}{ Parity $\wedge 2$} & -9.06 & .124 & .002 & .0005 \\
\hline & \multicolumn{2}{|c|}{$\pi_{0}^{W}$} & \multicolumn{2}{|c|}{$\pi_{0}^{A}$} \\
\hline Constant & 2659.60 & 6.658 & 37.71 & .029 \\
\hline
\end{tabular}

Note: SUR model based on ECLS-B full sample weights (w1r0). The p-value for all coefficients is less than 0.001, except for alcoholic drinks per week (squared term) in the birth weight equation ( $\mathrm{p}=0.003)$, and the separated, divorced or widowed indicator in the gestational age equation $(\mathrm{p}=0.075)$. 
Table 6 - Summary statistics

\begin{tabular}{|c|c|c|c|c|c|c|}
\hline \multicolumn{7}{|c|}{ Child outcomes (standardized) } \\
\hline Cognitive skill at age 3, Stanford Binet IQ & $h$ & -0.72 & 1.26 & -3.56 & 2.93 & 858 \\
\hline Cognitive skill at age 5, WPPSI IQ & & -0.54 & 1.17 & -3.73 & 2.93 & 758 \\
\hline Cognitive skill at age 8 , Wechsler IQ & & -0.92 & 1.84 & -6.00 & 4.60 & 820 \\
\hline Cognitive skill at age 18 , WASI IQ & & -0.53 & 1.08 & -3.33 & 2.20 & 582 \\
\hline \multicolumn{7}{|c|}{ Parental post-natal choices } \\
\hline Hours per week of maternal care & $r$ & 60.95 & 15.91 & 12.5 & 87.5 & 930 \\
\hline Hours per week at CDC & $t$ & 6.15 & 9.99 & 0 & 40.52 & 930 \\
\hline Hours per week with other caretakers & $n$ & 20.39 & 14.81 & 0 & 61 & 930 \\
\hline $\begin{array}{l}\text { Maternal-care quality, Learning and Literacy } \\
\text { components of the HOME score at age } 3\end{array}$ & $q^{r}$ & 0.12 & 0.98 & -1.94 & 1.49 & 768 \\
\hline Non-maternal care quality, predicted ORCE & $q^{n}$ & 3.68 & 0.20 & 2.87 & 4.17 & 820 \\
\hline Hours per week of working time & $L$ & 16.56 & 16.51 & 0 & 57 & 856 \\
\hline Hours per week of leisure & l & 92.25 & 15.94 & 32 & 151 & 856 \\
\hline \multicolumn{7}{|c|}{ Characteristics at birth } \\
\hline Birth weight (kilograms) & $h_{0}$ & 1.80 & 0.49 & 0.72 & 2.5 & 930 \\
\hline Gestational age at birth (weeks) & & 33.06 & 2.59 & 26 & 38 & 930 \\
\hline Expected potential wage, US\$2012 per hour & $\widehat{w}$ & 8.75 & 5.73 & 0.02 & 23.69 & 930 \\
\hline Pre-natal investment, percentile & $I_{0}^{*}$ & 0.27 & 0.23 & 0.01 & 0.93 & 930 \\
\hline Endowment shock, percentile & $\phi$ & 0.05 & 0.07 & 0.01 & 0.65 & 930 \\
\hline
\end{tabular}


Table 7 - Learning an Literacy components (IT-Home score) available in the IHDP sample

\begin{tabular}{|l|l|}
\hline 12-month Home Assessment & 36-month Home Assessment \\
\hline At least 10 books are present and visible & Child has toys which teach color, size, shape \\
\hline Muscle activity toys or equipment & Child has three or more puzzles \\
\hline Push or pull toys & Child has toys permitting free expression \\
\hline Parent provides toys for child during visit & $\begin{array}{l}\text { Child has toys or games requiring refined } \\
\text { movements }\end{array}$ \\
\hline $\begin{array}{l}\text { Learning equipment appropriate to age: } \\
\text { cuddly toys or role playing toys }\end{array}$ & Child has at least 10 children's books \\
\hline $\begin{array}{l}\text { Learning facilitators: mobile, table and } \\
\text { chairs, high chair, play pen }\end{array}$ & At least 10 books are visible in the apartment \\
\hline Complex eye-hand coordination toys & Child is encouraged to learn the alphabet \\
\hline Toys for literature and music & $\begin{array}{l}\text { Interior of apartment not dark or perceptually } \\
\text { monotonous }\end{array}$ \\
\hline $\begin{array}{l}\text { Parent reads stories to child at least } 3 \text { times } \\
\text { weekly }\end{array}$ & $\begin{array}{l}\text { Parent converses with child at least twice } \\
\text { during visit }\end{array}$ \\
\hline $\begin{array}{l}\text { Child has } 3 \text { or more books of her own } \\
\text { relationships }\end{array}$ \\
\hline $\begin{array}{l}\text { Child is encouraged to learn to read a few } \\
\text { words }\end{array}$ \\
\hline Child has real or toy musical instrument \\
\hline
\end{tabular}

Based on Linver, Martin and Brooks-Gunn (2004) and Fuligni, Han and Brooks-Gunn (2004). 
Table 8 - Treatment effect of the IHDP intervention on cognitive development

\begin{tabular}{|c|c|c|c|c|c|}
\hline & & (1) & (2) & (3) & (4) \\
\hline & Age & $\begin{array}{c}36 \text { months } \\
\text { (3 years) }\end{array}$ & 5 years & 8 years & 18 years \\
\hline & IQ test & Stanford Binet & WPPSI & Wechsler & WASI \\
\hline Treatment indicator & $(\mathrm{T})$ & $0.733 * * *$ & $0.277^{*}$ & 0.366 & 0.0300 \\
\hline & & $(0.0897)$ & $(0.133)$ & $(0.207)$ & $(0.135)$ \\
\hline Potential wage above $33^{\text {rd }}$ percentile & $(\mathrm{HW})$ & $0.528 * * *$ & $0.603 * * *$ & $0.797 * *$ & $0.431 * *$ \\
\hline & & $(0.130)$ & $(0.168)$ & $(0.246)$ & $(0.150)$ \\
\hline Treatment $x$ Potential wage above $33^{\text {rd }}$ perc. & $(\mathrm{T} \times \mathrm{HW})$ & $-0.265^{*}$ & $-0.292 *$ & $-0.413 * *$ & -0.0623 \\
\hline & & $(0.126)$ & $(0.150)$ & $(0.148)$ & $(0.0904)$ \\
\hline Prenatal Investment above $33^{\text {rd }}$ percentile & (HI) & $0.268 * * *$ & $0.319 * *$ & $0.495 * *$ & $0.240 * * *$ \\
\hline & & $(0.0605)$ & $(0.0935)$ & $(0.178)$ & $(0.0643)$ \\
\hline Treatment $x$ Prenatal Investment above $33^{\text {rd }}$ perc. & $(\mathrm{T} \times \mathrm{HI})$ & 0.0801 & -0.0633 & -0.0742 & 0.0416 \\
\hline & & $(0.0989)$ & $(0.0966)$ & $(0.236)$ & $(0.127)$ \\
\hline Percentile of Endowment & & -0.307 & $-0.746^{* *}$ & 0.554 & 0.0142 \\
\hline & & $(0.347)$ & $(0.271)$ & $(0.594)$ & $(0.473)$ \\
\hline Constant & & $-1.321 * * *$ & $-1.298 * * *$ & $-1.994 * * *$ & $-1.260 * * *$ \\
\hline & & $(0.118)$ & $(0.139)$ & $(0.164)$ & $(0.128)$ \\
\hline Observations & & 858 & 758 & 820 & 582 \\
\hline R-squared & & 0.259 & 0.203 & 0.176 & 0.220 \\
\hline
\end{tabular}

Note: The measurement units of all the dependent variables (IQ tests) are standard deviations. $\mathrm{T}=1$ for individuals included in the treatment group; HW $=1$ if the mother's expected potential wage $(\widehat{w})$ is above the $33^{\text {rd }}$ percentile of the distribution within the sample; $\mathrm{HI}=1$ if the prenatal investment index $\left(I_{0}^{*}\right)$ is above the $33^{\text {rd }}$ percentile of the distribution within the sample. All regressions include location (site) indicators. Robust standard errors in parentheses. ${ }^{* *} \mathrm{p}<0.01, * * \mathrm{p}<0.05,{ }^{*} \mathrm{p}<0.1$. 
Table 9 - Treatment effect of the IHDP intervention on inputs in the production of cognitive skills

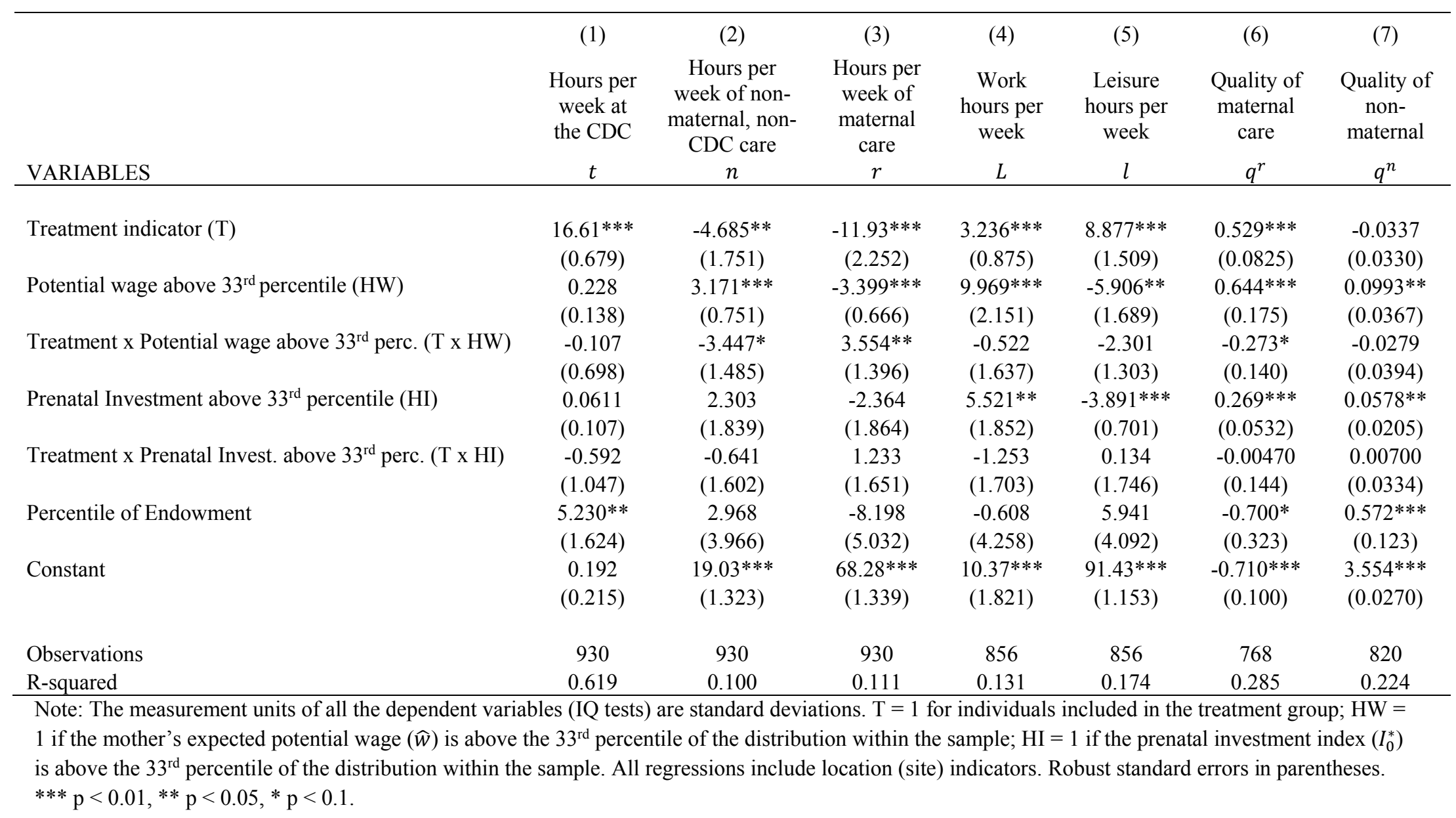




\section{Figures}

Figure 1 - Distribution of pre-natal investment and endowment indexes, ECLS-B and IHDP samples

(a)

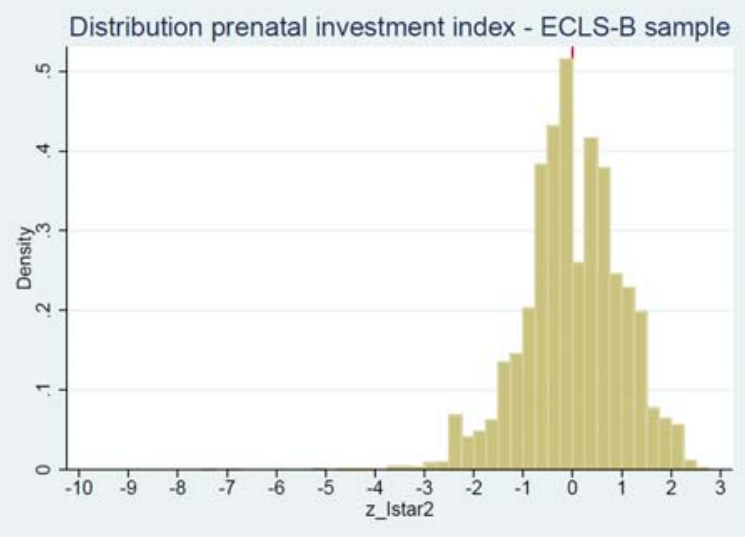

(b)

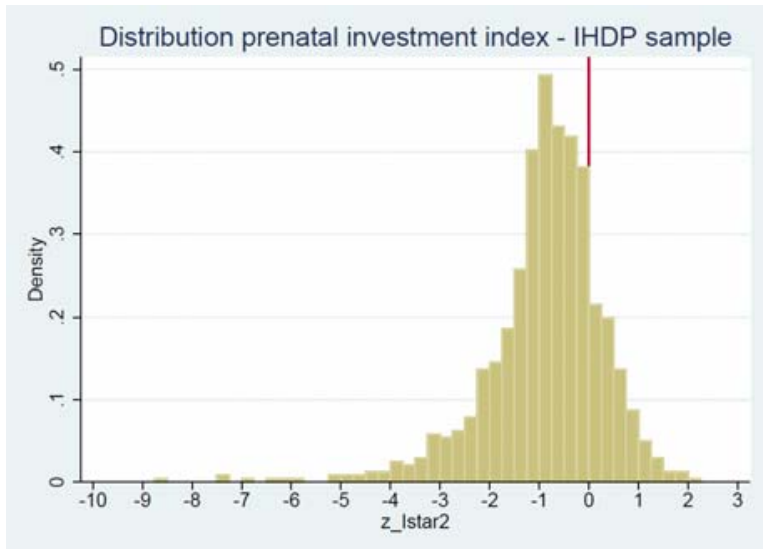

(c)

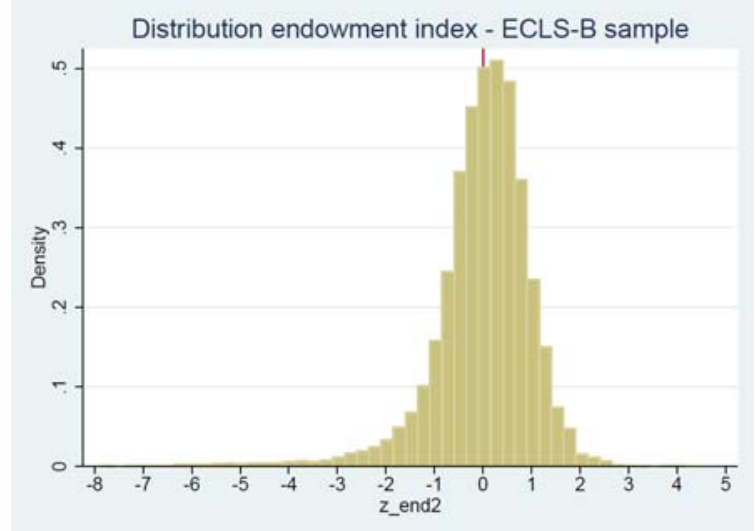

(d)

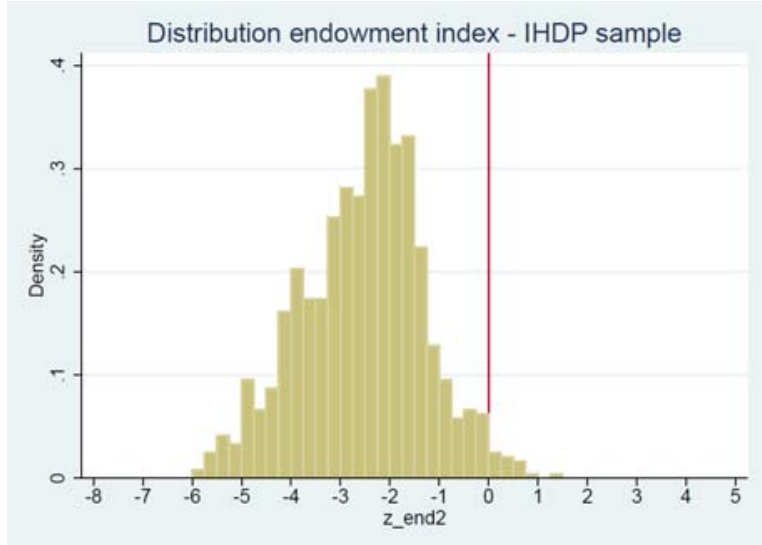

Note: all units are standard deviations from the ECLS-B distribution. 
Figure 2 - Predicted IQ at 36 months for IHDP treatment and control groups (National average $=100$; Standard deviation $=16)$
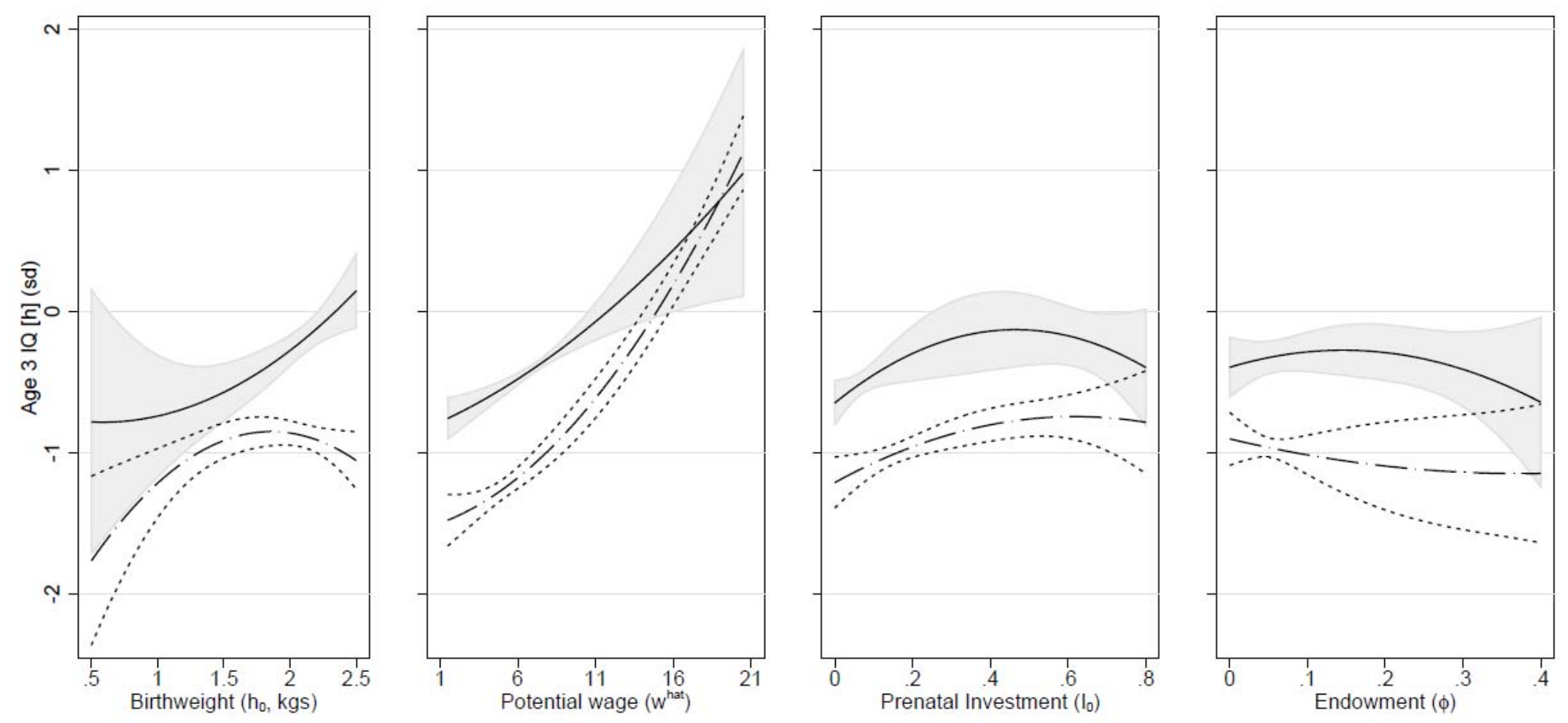

Treatment: solid line. Control: dashed line. 95\% confidence intervals. Potential wage: US\$ of 2012 per hour. Endowment and Prenatal Investment. percentile in ECLS-B distribution. $\mathrm{N}=858$. 
Figure 3 - IHDP treatment effects on IQ at 36 months
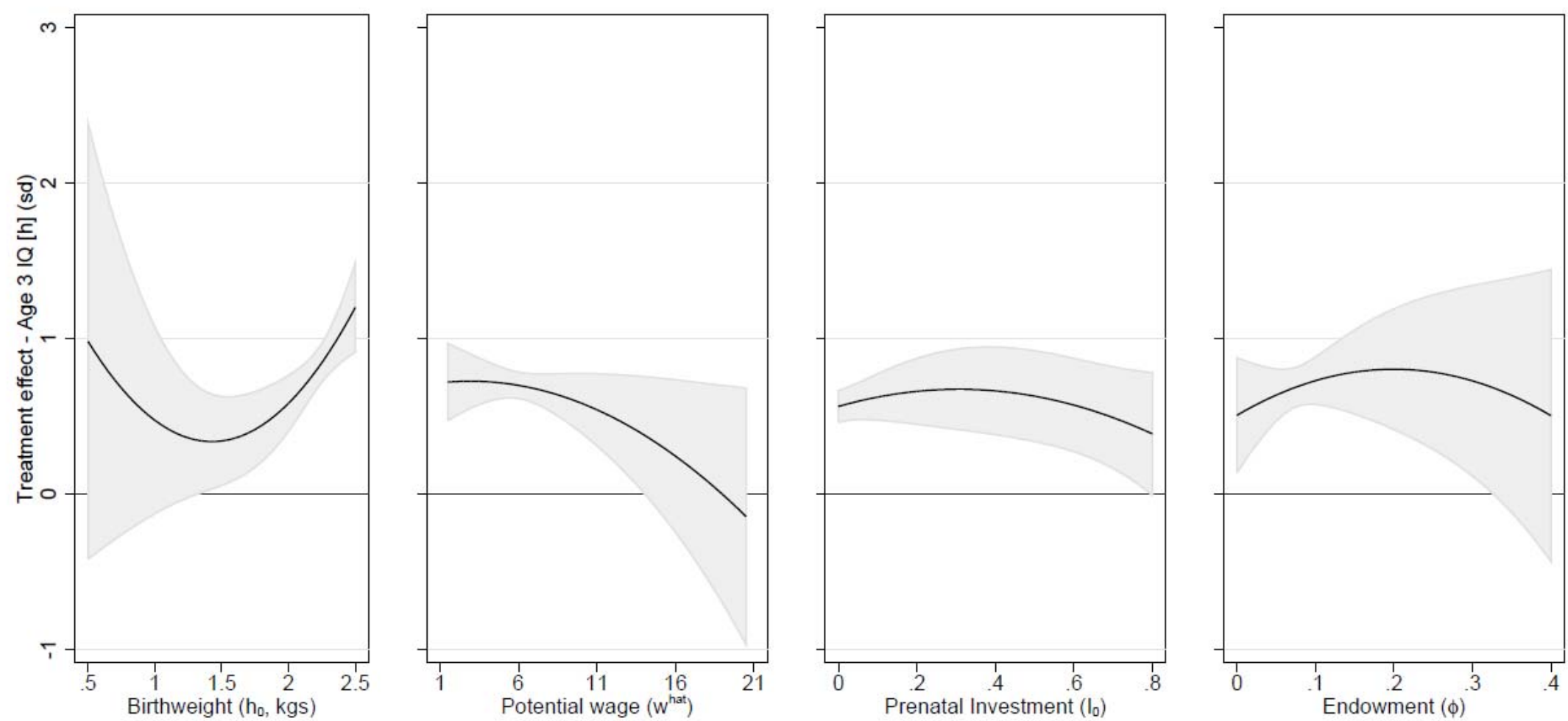

Estimate and 95\% confidence interval. Potential wage: US $\$$ of 2012 per hour. Endowment and Prenatal Investment: percentile in ECLS-B distribution. N $=858$ 
Figure 4 - IHDP treatment effects on hours per week of CDC use $(t)$
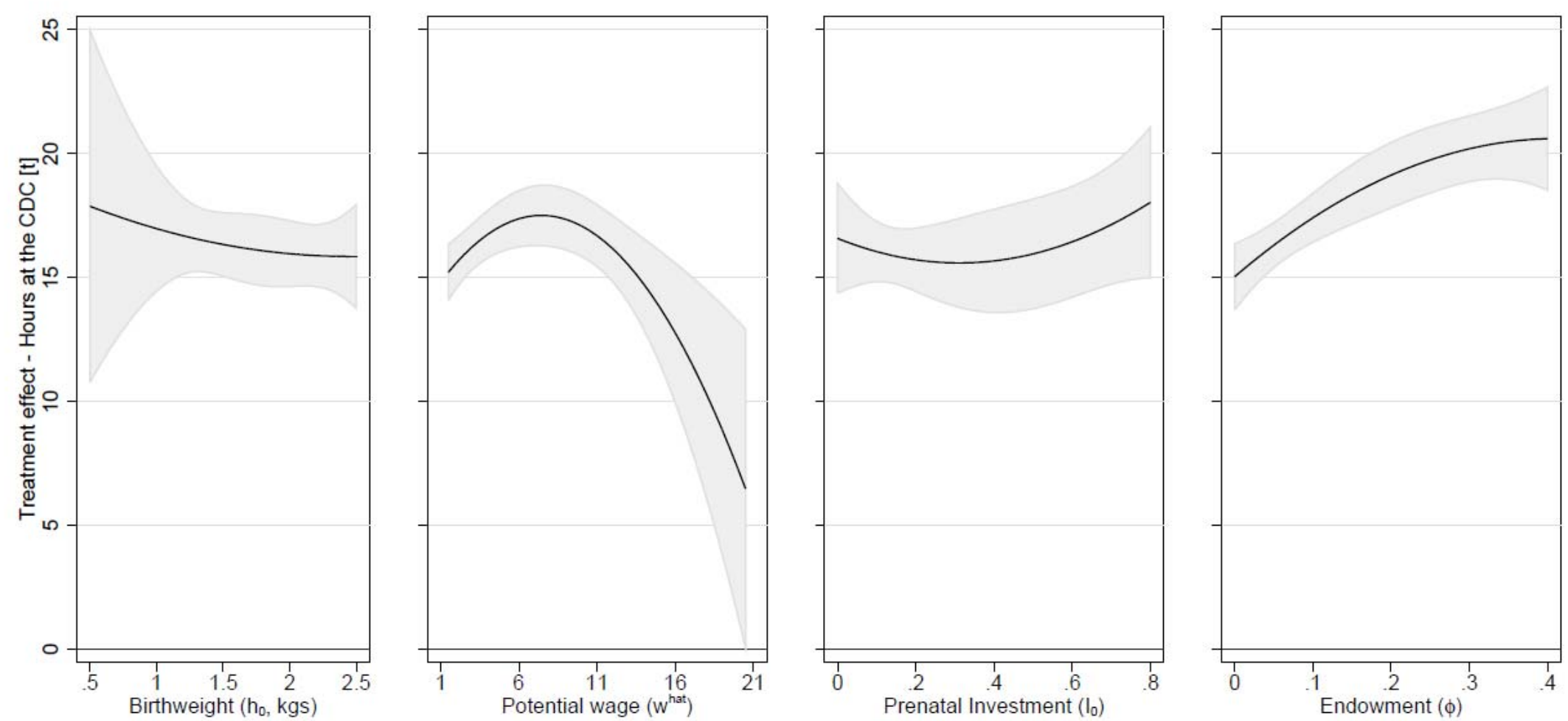

Estimate and 95\% confidence interval. Potential wage: US\$ of 2012 per hour. Endowment and Prenatal Investment: percentile in ECLS-B distribution. N = 930 . 
Figure 5 - IHDP treatment effects on hours per week of non-maternal care $(n)$
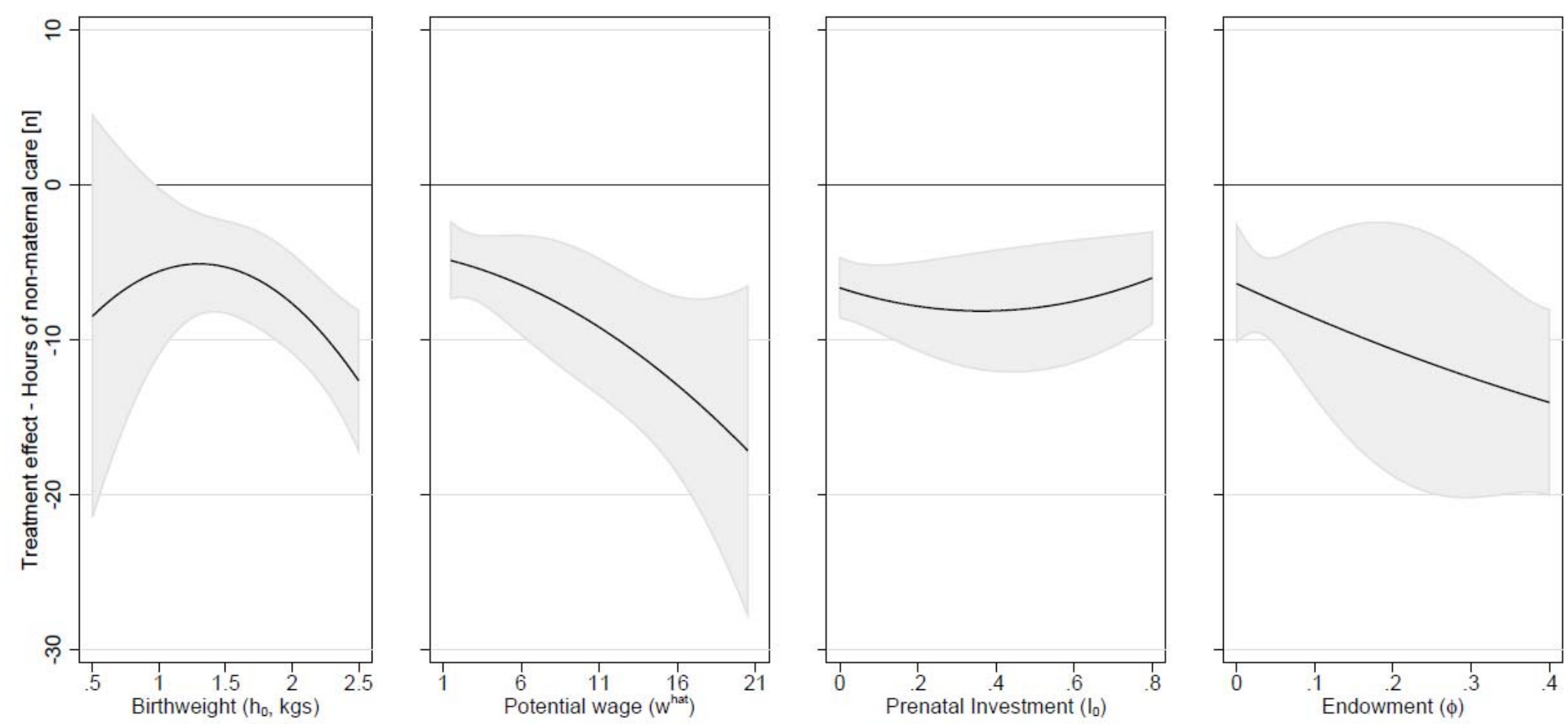

Estimate and 95\% confidence interval. Potential wage: US\$ of 2012 per hour. Endowment and Prenatal Investment: percentile in ECLS-B distribution. N = 930 . 
Figure 6 - IHDP treatment effects on hours per week of -maternal care $(r)$
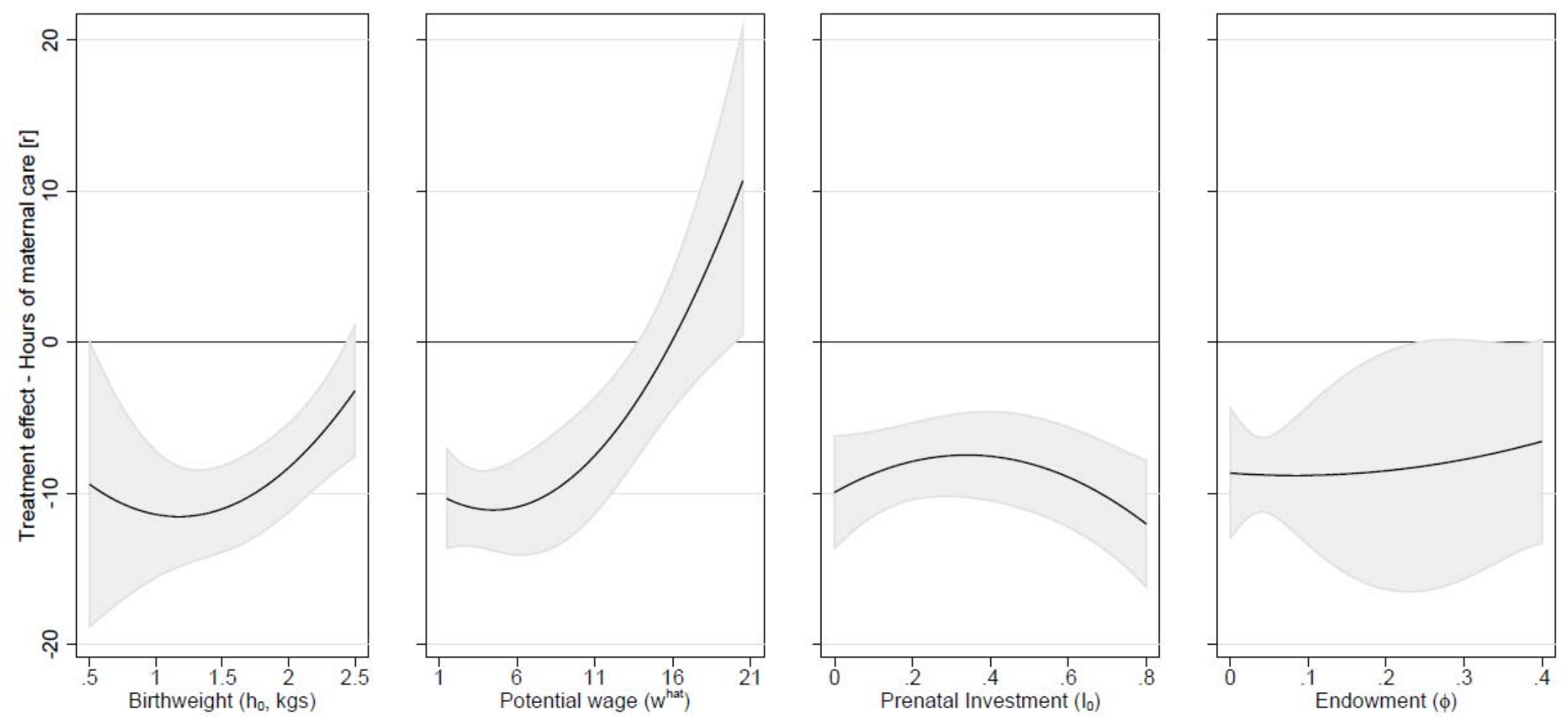

Estimate and 95\% confidence interval. Potential wage: US $\$$ of 2012 per hour. Endowment and Prenatal Investment: percentile in ECLS-B distribution. N $=930$ 
Figure 7 - IHDP treatment effects on work hours $(L)$
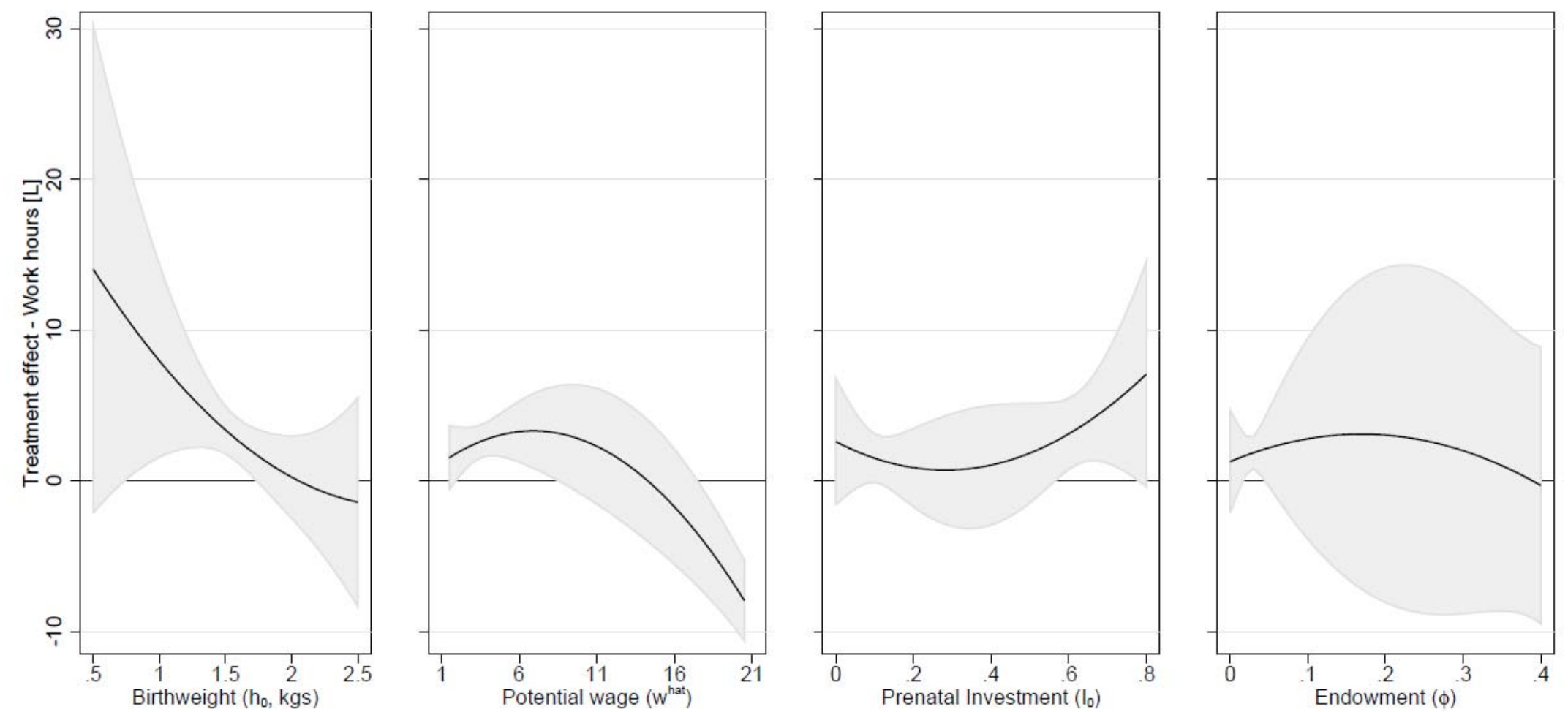

Estimate and 95\% confidence interval. Potential wage: US $\$$ of 2012 per hour. Endowment and Prenatal Investment. percentile in ECLS-B distribution. N $=856$ 
Figure 8 - IHDP treatment effects on leisure time $(l)$
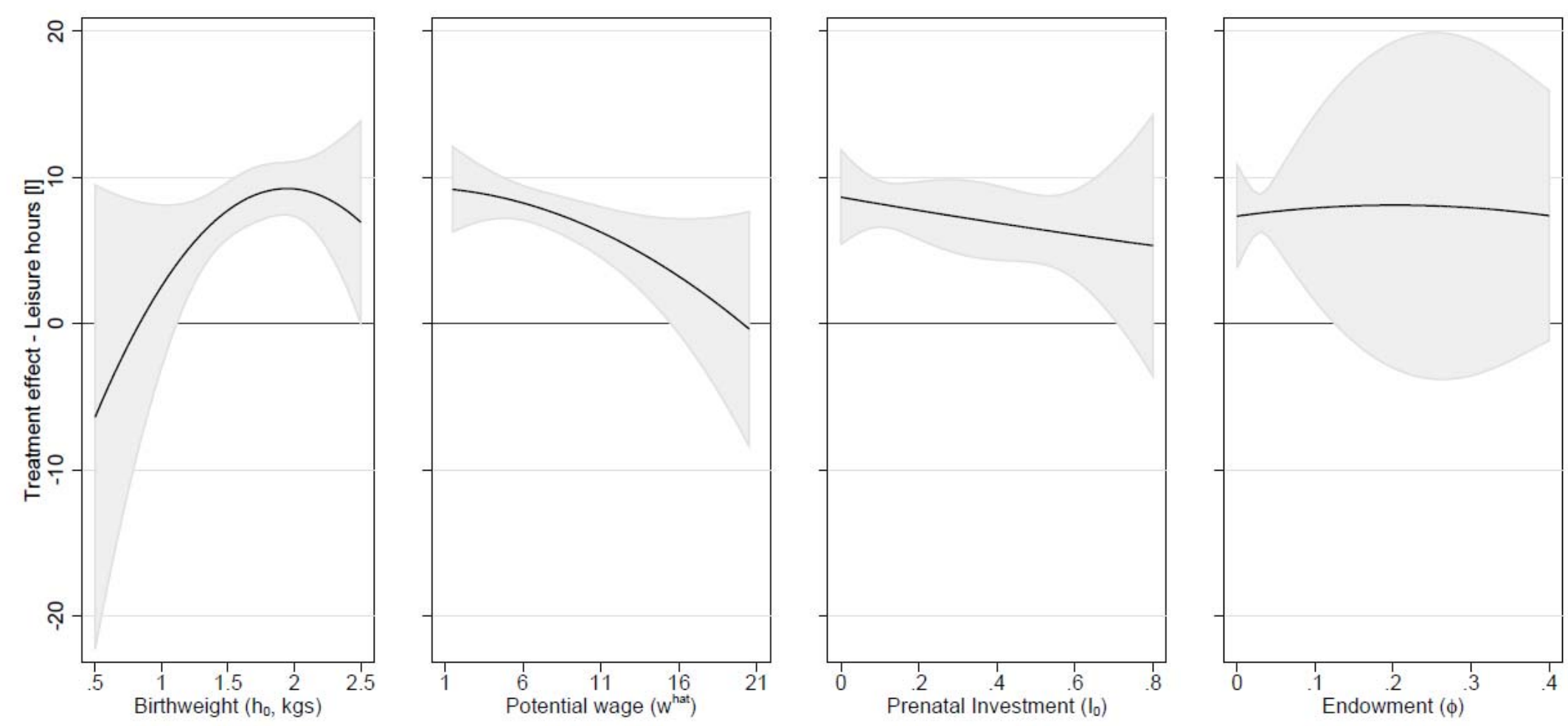

Estimate and 95\% confidence interval. Potential wage: US\$ of 2012 per hour. Endowment and Prenatal Investment: percentile in ECLS-B distribution. N $=856$ 
Figure 9 - IHDP treatment effects on quality of maternal care $\left(q^{r}\right)$
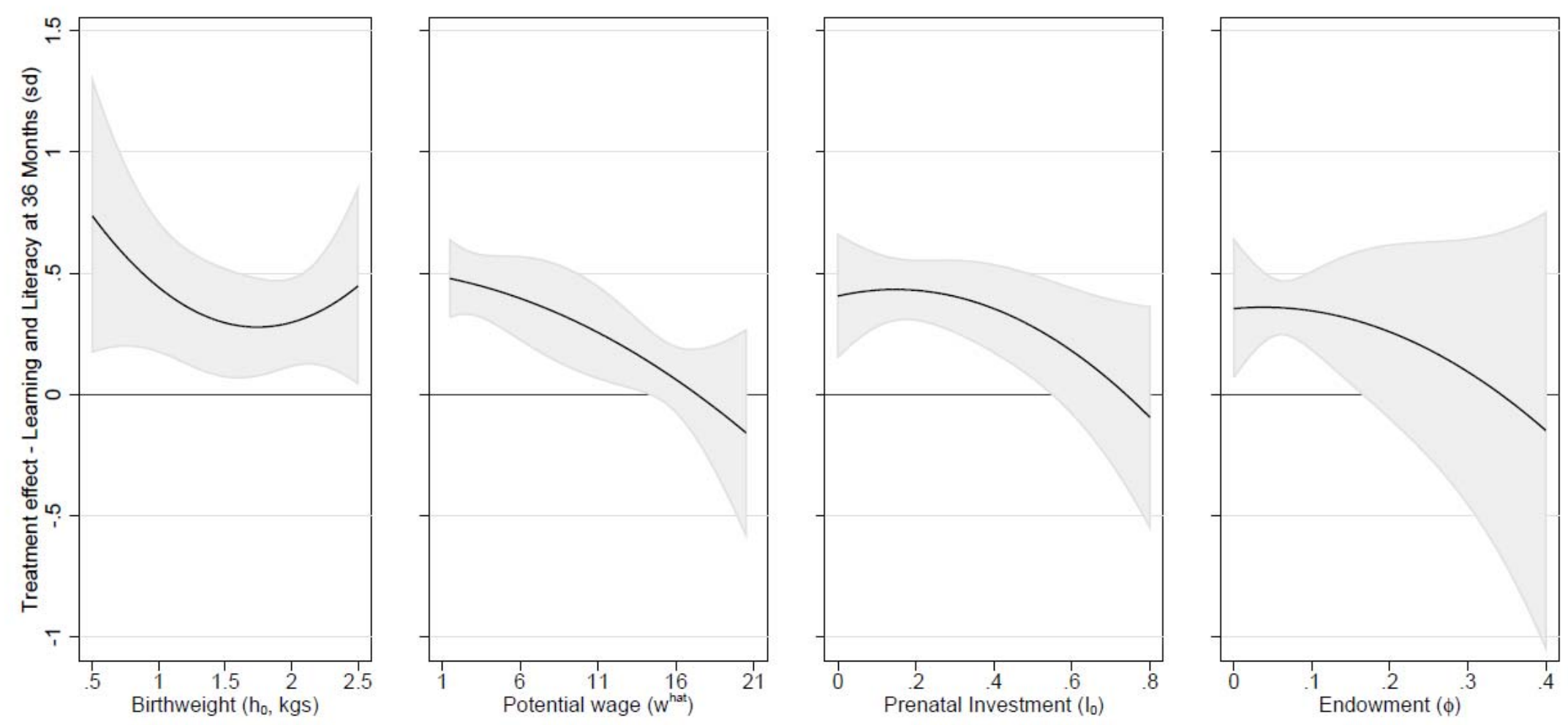

Estimate and 95\% confidence interval. Potential wage: US $\$$ of 2012 per hour. Endowment and Prenatal Investment: percentile in ECLS-B distribution. N $=768$ 
Figure 10 - IHDP treatment effects on quality of non-maternal care $\left(q^{n}\right)$
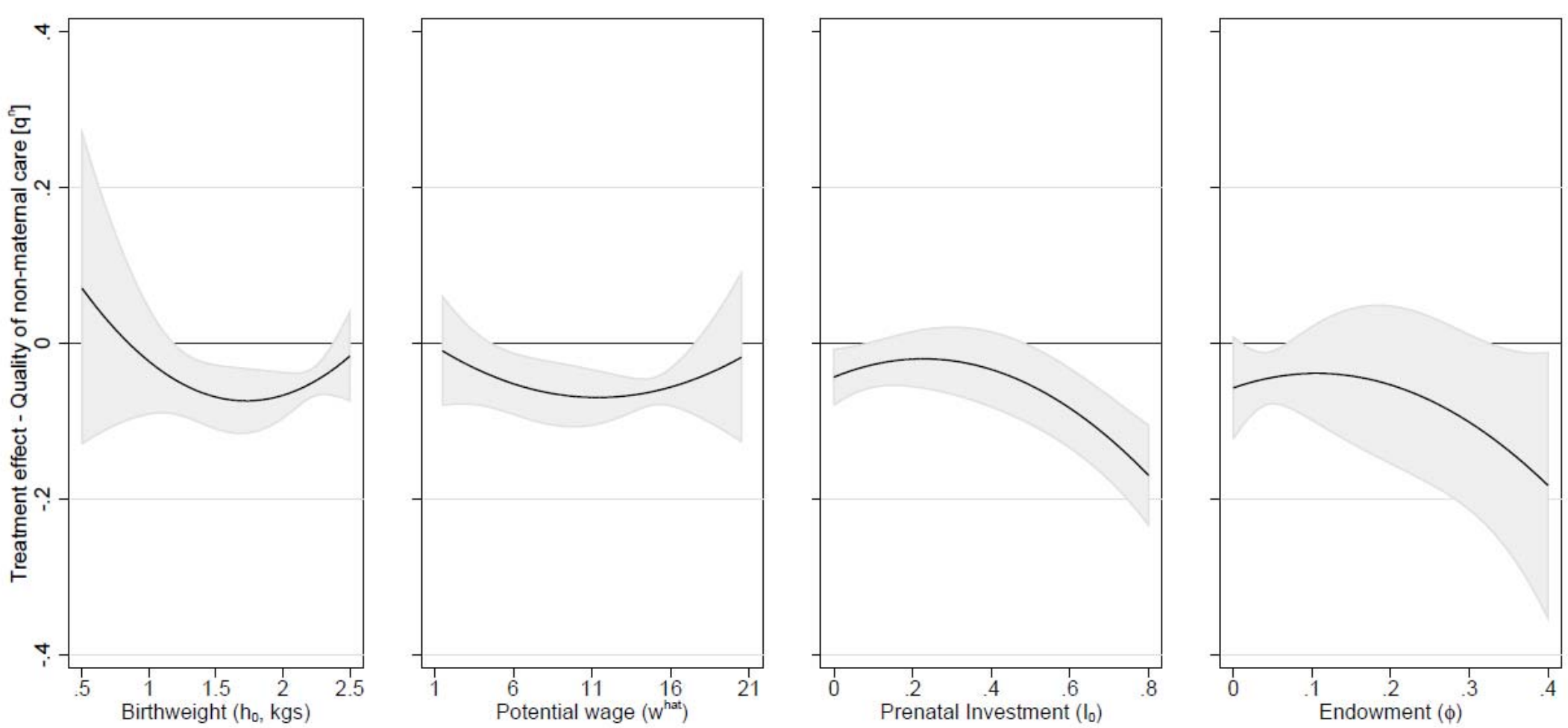

Estimate and 95\% confidence interval. Potential wage: US $\$$ of 2012 per hour. Endowment and Prenatal Investment. percentile in ECLS-B distribution. N $=820$ 


\section{Appendixes}

10.1 Appendix 1: Kuhn-Tucker conditions for the post-natal parental problem

$$
\frac{\partial \mathcal{L}}{\partial \lambda}=w\left[T_{p}-T_{c}\right]+w t+Y-c-\left[\pi q^{n}-w\right] n-w l=0
$$$$
\lambda \geq 0
$$

$\frac{\partial \mathcal{L}}{\partial \mu}=\bar{\tau}-t \geq 0$

$$
\frac{\partial \mathcal{L}}{\partial \mu} \mu=0 \quad \mu \geq 0
$$

$\frac{\partial \mathcal{L}}{\partial c}=U_{c}-\lambda \leq 0$

$$
\frac{\partial \mathcal{L}}{\partial c} c=0
$$

$\frac{\partial \mathcal{L}}{\partial q^{n}}=U_{h} f_{1} n-\lambda \pi n \leq 0$

$$
\frac{\partial \mathcal{L}}{\partial q^{n}} q^{n}=0 \quad q^{n} \geq 0
$$

$\frac{\partial \mathcal{L}}{\partial e}=U_{p} r+U_{h} f_{2} q_{e}^{r} r \leq 0$

$$
\frac{\partial \mathcal{L}}{\partial e} e=0 \quad e \geq 0
$$

$\frac{\partial \mathcal{L}}{\partial n}=U_{h}\left[f_{1} q^{n}-f_{2} q^{r}\right]-U_{p} e-\lambda\left[\pi q^{n}-w\right] \leq 0$

$\frac{\partial \mathcal{L}}{\partial n} n=0 \quad n \geq 0$

$\frac{\partial \mathcal{L}}{\partial l}=U_{l}-\lambda w \leq 0$

$\frac{\partial \mathcal{L}}{\partial l} l=0 \quad l \geq 0$

$\frac{\partial \mathcal{L}}{\partial t}=U_{h}\left[f_{1} q^{t}-f_{2} q^{r}\right]+U_{t}-U_{p} e+\lambda w-\mu \leq 0$

$\frac{\partial \mathcal{L}}{\partial t}[t-\bar{\tau}]=0 \quad 0 \leq t \leq \bar{\tau}$ 


\section{Quality of nonmaternal care}

The IHDP data has very specific information about non-maternal care. The survey asked for the primary and secondary caregivers during a typical week at the 18-month, 24-month, 30-month and 36-month family interviews. The respondent could choose from nine different categories (partner, sibling, grandmother, another relative, babysitter, day care home, day care center, someone else and the child's father, if he lives in another home). However, the IHDP did not directly measure the quality of non-maternal care.

To get a continuous measure the quality of these care settings, we draw in data from a pioneering study of nonmaternal care quality, the Study of Early Child Care and Youth Development (SECCYD) by the National Institute of Child Health and Human Development (NICHD). The SECCYD collected panel data on child and family characteristics and their use of various care settings. The SECCYD classifies non-maternal caregivers into nine categories: father / partner, grandparent in-home, grandparent out-of-home, other relative in-home, other relative out-ofhome, non-relative in-home, non-relative out-of-home, child care center and others. The study included a sample of 1,364 children aged 0 to 3 during 1991 to 1994 in 10 study sites around the country, 2 of which overlap with the IHDP's 8 sites. ${ }^{18}$

For each child and each nonmaternal care setting used, the SECCYD measured care quality using the Observational Record of the Childcare Environment (ORCE) (NICHD, 2003; Vandell, 2004), which is composed of three different types of scores: Behavioral Scales, Qualitative Ratings and measures of Structural Variables. We follow Auger \& Burchinal (2013), who suggest that a good measure of the quality of interactions geared toward cognitive stimulus is the ORCE's Qualitative Rating on Stimulation of Development. This rating is available in the SECCYD data at 15, 24 and 36 months (Phase 1).

We estimate a pooled OLS model in the SECCYD data, in which the dependent variable is standardized ORCE Qualitative Rating on Stimulation of Development. The set of predictors must be variables available in both the SECCYD and IHDP datasets. They include child's age, birth order, gender, birth weight (level and square), gestational age at birth (level and square), maternal age at child birth, maternal education (four categories), race, ethnicity, marital status, and study site. As a predictor, we also use the standardized Learning and Literacy score based on components from the HOME score (Linver, Martin \& Brooks-Gunn, 2004; Fuligni, Han \& Brooks-Gunn, 2004). Finally, we match the nine categories of non-maternal caregivers from the

\footnotetext{
${ }^{18}$ The 10 sites of the SECCYD - NICHD study are University of Arkansas, UC Irvine, University of Kansas, University of New Hampshire, Penn State University, Temple University, University of Virginia, University of Washington, Western Carolina Center and University of Wisconsin. The sites which overlap with the IHDP study are the University of Arkansas and the University of Washington.
} 
IHDP with the nine categories used in the SECCYD. Thus, the last set of predictors is indicators for the category of the caregiver.

After estimating the linear relationship between mean nonmaternal care quality and the set of predictors in the SECCYD, we score each IHDP child based on the same set of predictors and impute that mean prediction as the IHDP child's measure of nonmaternal-care quality $\left(\tilde{q}^{n}\right)$. Summary statistics for the SECCYD data and model estimates are displayed in Appendix Tables AT.1 and AT.2, respectively.

To pin down the price of nonmaternal care $(\pi)$ and the scale of our nonmaternal care quality measure $\left(q^{n}\right)$, we calibrate to data on average hourly child care prices from a conveniently-timed, nationally-representative survey of home- and center-based providers carried out during 19891990 (Kisker, Hofferth, Phillips, \& Farquar, 1991). We normalize the location of $q^{n}$ to match the average quality of center-based care in the SECCYD: $q_{\text {center }}^{n} \equiv \tilde{q}_{\text {center }}^{n}=3.62$.

Next, we calibrate $\pi$ using price data. The average price of an hour of center-based care for children 12-36 months of age was $\$ 2.82$ (2012\$). In our model, the hourly price of care is $p\left(q^{n}\right)=$ $\pi q^{n}$. This implies $\pi=\$ 0.7796=\$ 2.82 / 3.62$.

By combining data on the differences in price and quality between home-based and center-based care, we calibrate $q^{n}$ to have a meaningful scale. Our model implies that two care settings with quality difference $\Delta q^{n}$ will have hourly price difference $\Delta p=\pi \Delta q^{n} .{ }^{19}$ Therefore, the average observed quality of home-based care should obey:

$$
q_{\text {home }}^{n}=q_{\text {center }}^{n}+\frac{\Delta p}{\pi}
$$

The observed difference in average hourly price between home-based care and center-based care is $\Delta p=\$ 0.09$ (Kisker, Hofferth, Phillips, \& Farquar, 1991). The equation above implies that $q_{\text {home }}^{n}=3.74$ and, so, this implies that $\Delta q^{n}=3.74-3.62=0.12$. In the original quality metric, $\Delta \tilde{q}^{n}=0.58$. The ratio of these quality differences is 0.207 . Therefore, to convert from an arbitrary quality scale to a scale grounded in observed price differences, we set $q^{n} \equiv$ $0.207\left(\tilde{q}^{n}-3.62\right)$.

In order to calculate the heterogeneous treatment effects on the quality of non-maternal care, we standardize $q^{n}$ within the IHDP sample.

\footnotetext{
${ }^{19}$ Kisker et al (1991) contains substantial evidence that, consistent with our model, hourly prices rise in quality. For instance, settings with lower child-teacher ratios and a higher share of teachers with a college degree charge higher average prices.
} 


\section{Appendix Tables and Figures}

AT. 1: Descriptive statistics from the NICHD - SECCYD data

\begin{tabular}{|c|c|c|c|c|c|}
\hline & Mean & Std. Dev. & Min & Max & $\mathrm{N}$ \\
\hline ORCE, Stimulation of Development score & 0.00 & 1.00 & -1.39 & 3.26 & 1,837 \\
\hline Child's age (months) & 25.29 & 8.64 & 15 & 36 & 1,837 \\
\hline Birth order & 1.67 & 0.81 & 1 & 5 & 1,837 \\
\hline Female indicator & 0.49 & 0.50 & 0 & 1 & 1,837 \\
\hline Child's birth weight (kgs) & 3.50 & 0.51 & 2 & 5.34 & 1,837 \\
\hline Child's gestational age (weeks) & 39.27 & 1.47 & 33 & 43 & 1,837 \\
\hline Mother's age (years) & 28.92 & 5.39 & 18 & 46 & 1,837 \\
\hline Learning and Literacy Score, HOME Inventory & 5.02 & 0.89 & 0 & 6.13 & 1,837 \\
\hline Mother's Education & Percent & & & & \\
\hline Less than High School & 4.9 & & & & \\
\hline High School graduate & 17.8 & & & & \\
\hline Some College & 35.0 & & & & \\
\hline College graduate & 42.4 & & & & \\
\hline Race and Ethnicity & Percent & & & & \\
\hline Non-Hispanic White & 82.6 & & & & \\
\hline African American & 10.3 & & & & \\
\hline Hispanic & 4.3 & & & & \\
\hline Other & 2.7 & & & & \\
\hline Non-Maternal Caregiver & Percent & & & & \\
\hline Father / Partner & 14.8 & & & & \\
\hline Grandparent & 10.3 & & & & \\
\hline Another Relative & 5.6 & & & & \\
\hline Non-Relative In-Home & 10.8 & & & & \\
\hline Day Care Home & 27.3 & & & & \\
\hline Child Care Center & 31.3 & & & & \\
\hline
\end{tabular}


AT. 2: Model estimates for the quality of non-maternal care in the SECCYD - NICHD data

Child's age indicator, 24 months $\quad 0.0305$

$0.0940^{*}$

$(0.0500)$

Child's birth order

$-0.125^{* * *}$

$(0.0348)$

Female child indicator

$0.123 * *$

$(0.0536)$

Birth weight (grams)

0.412

(0.472)

Birth weight squared

$-0.0571$

$(0.0661)$

Child's gestational age

$0.884 *$

$(0.511)$

Child's gestational age squared

$-0.0114^{*}$

$(0.00663)$

Mother's age

$0.0106^{*}$

$(0.00625)$

Mother's education: Less than High School

0.0228

$(0.126)$

Mother's education: Some college

0.0943

$(0.0722)$

0.150 *

Mother's education: College graduate

$(0.0802)$

Race and ethnicity: African-American

$-0.194 * *$

(0.0861)

$-0.104$

Race and ethnicity: Hispanic

$(0.143)$

0.179

(0.128)

$-0.132$

Marital status: Single

$(0.0916)$

$-0.260$

Marital status: Separated / Divorced / Widowed

Avg. Learning and Literacy score, $15 \mathrm{~m}$ and $36 \mathrm{~m}$

$0.142 * * *$

$(0.0339)$

Non-Maternal Caregiver: Father / Partner

$0.336 * * *$

$(0.0889)$

Non-Maternal Caregiver: Grandparent

$0.342 * * *$

$(0.0949)$

Non-Maternal Caregiver: Another Relative

0.0302

(0.104)

Non-Maternal Caregiver: Non-Relative In-Home

$0.534 * * *$

Non-Maternal Caregiver: Day Care Home

$(0.105)$

$0.138 * *$ 
$(0.0661)$

Constant

$-18.94 * *$

(9.626)

Observations

1,837

R-squared

0.140

Note: the dependent variable is the Observational Rating of the Caregiving Environment (ORCE), Stimulation of Development score. The excluded child's age category is 15 months. The excluded mother's education category is high school graduates. The excluded race and ethnicity category are non-hispanic whites. The excluded marital status category is married women. The excluded non-maternal caregiver category is child care centers. 9 site dummies are included but not reported. 
AT. 3: Treatment effect at 12 months on HOME score and Bayley test

\begin{tabular}{|c|c|c|}
\hline VARIABLES & $\begin{array}{c}\text { (1) } \\
\text { HOME Total Score } \\
\text { at } 12 \text { Months }\end{array}$ & $\begin{array}{c}\text { (2) } \\
\text { Bayley Mental Index- } \\
\text { Corrected Age }\end{array}$ \\
\hline Treatment indicator $=1$ & $\begin{array}{c}-0.0636 \\
(0.187)\end{array}$ & $\begin{array}{c}0.180 \\
(0.106)\end{array}$ \\
\hline Potential wage above 33 th percentile $=1$ & $\begin{array}{c}0.642 * * * \\
(0.172)\end{array}$ & $\begin{array}{l}0.210 * * \\
(0.0863)\end{array}$ \\
\hline Treatment $x$ Pot. Wage $>$ 33th perc. & $\begin{array}{c}0.0673 \\
(0.0905)\end{array}$ & $\begin{array}{l}-0.222 \\
(0.144)\end{array}$ \\
\hline Prenatal Invest. above 33 th perc. $($ in sample $)=1$ & $\begin{array}{c}0.262 * * * \\
(0.0702)\end{array}$ & $\begin{array}{l}0.208 * * \\
(0.0877)\end{array}$ \\
\hline Treatment x Prenatal Invest. $>$ 33th perc. & $\begin{array}{l}0.0516 \\
(0.215)\end{array}$ & $\begin{array}{c}-0.00242 \\
(0.153)\end{array}$ \\
\hline Percentile of Endowment & $\begin{array}{c}-1.418^{* *} \\
(0.484)\end{array}$ & $\begin{array}{c}0.715^{* *} \\
(0.288)\end{array}$ \\
\hline Constant & $\begin{array}{c}-0.507^{* * *} \\
(0.117)\end{array}$ & $\begin{array}{c}0.196^{*} \\
(0.0852)\end{array}$ \\
\hline $\begin{array}{l}\text { Observations } \\
\text { R-squared }\end{array}$ & $\begin{array}{c}828 \\
0.195\end{array}$ & $\begin{array}{c}846 \\
0.142\end{array}$ \\
\hline
\end{tabular}

Robust standard errors in parentheses

$* * * \mathrm{p}<0.01, * * \mathrm{p}<0.05, * \mathrm{p}<0.1$ 
Appendix Figure 1: Heterogeneity in treatment effects on Age 5 IQ
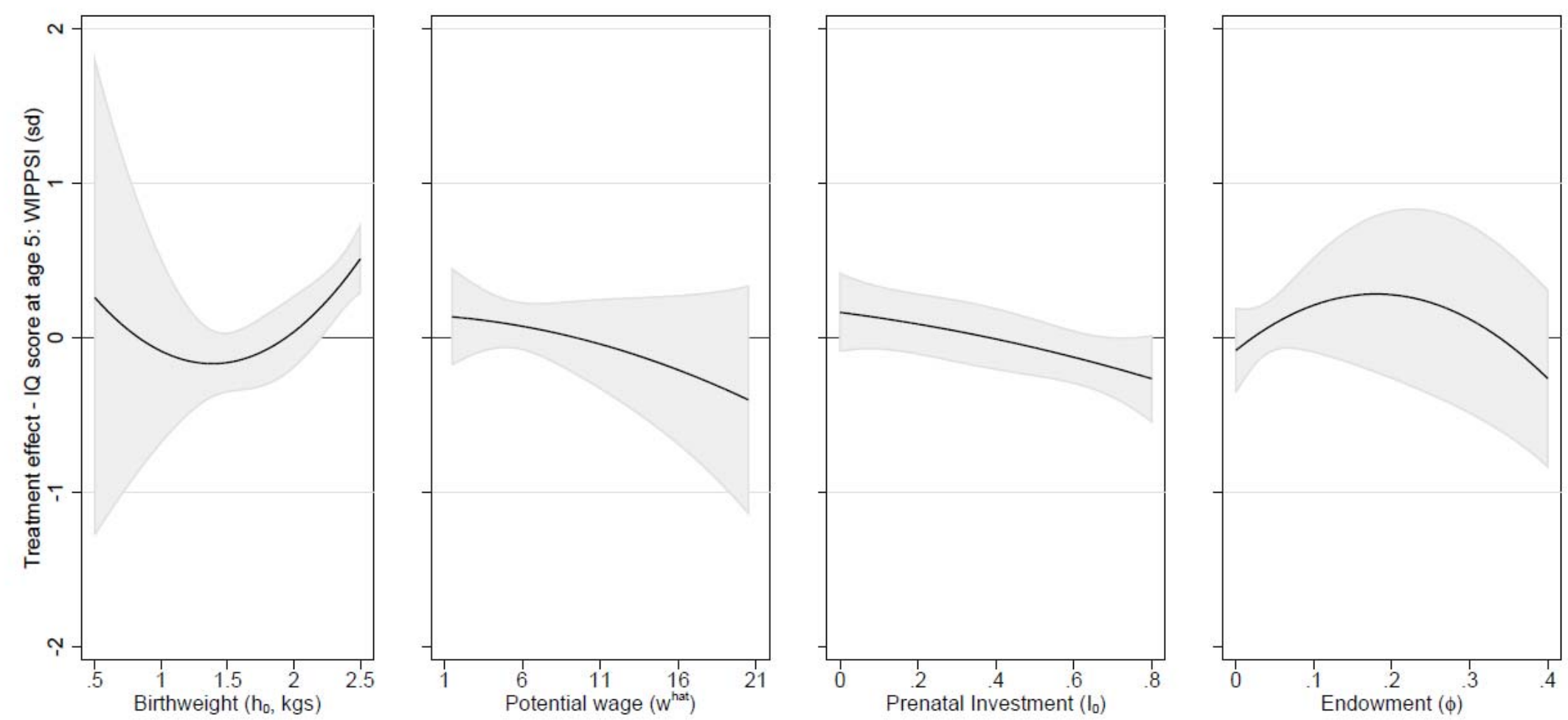

Estimate and 95\% confidence interval. Potential wage: US\$ of 2012 per hour. Endowment and Prenatal Investment: percentile in ECLS-B distribution. N= 758 . 
Appendix Figure 2: Heterogeneity in treatment effects on Age 8 IQ
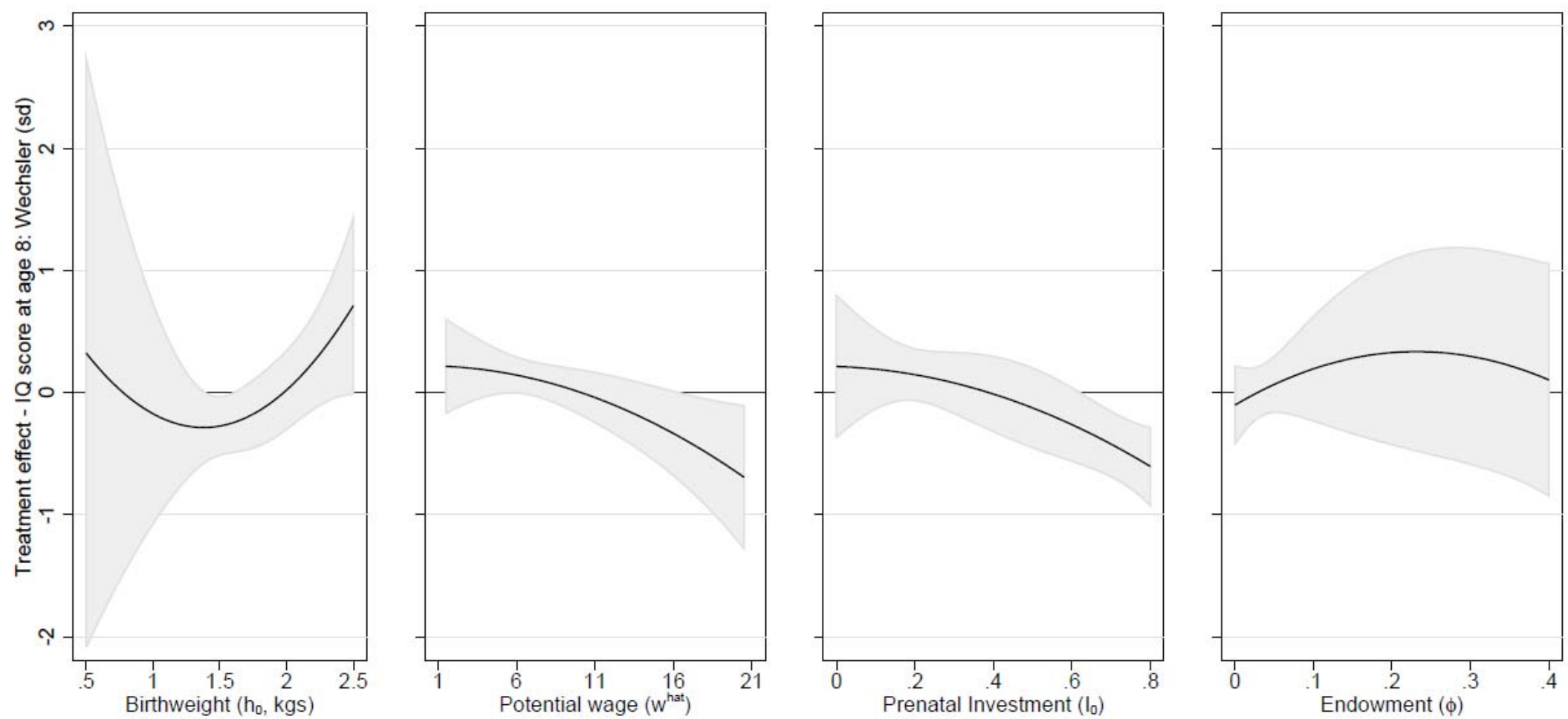

Estimate and 95\% confidence interval. Potential wage: US\$ of 2012 per hour. Endowment and Prenatal Investment: percentile in ECLS-B distribution. N $=820$ 
Appendix Figure 3: Heterogeneity in treatment effects on Age 18 IQ
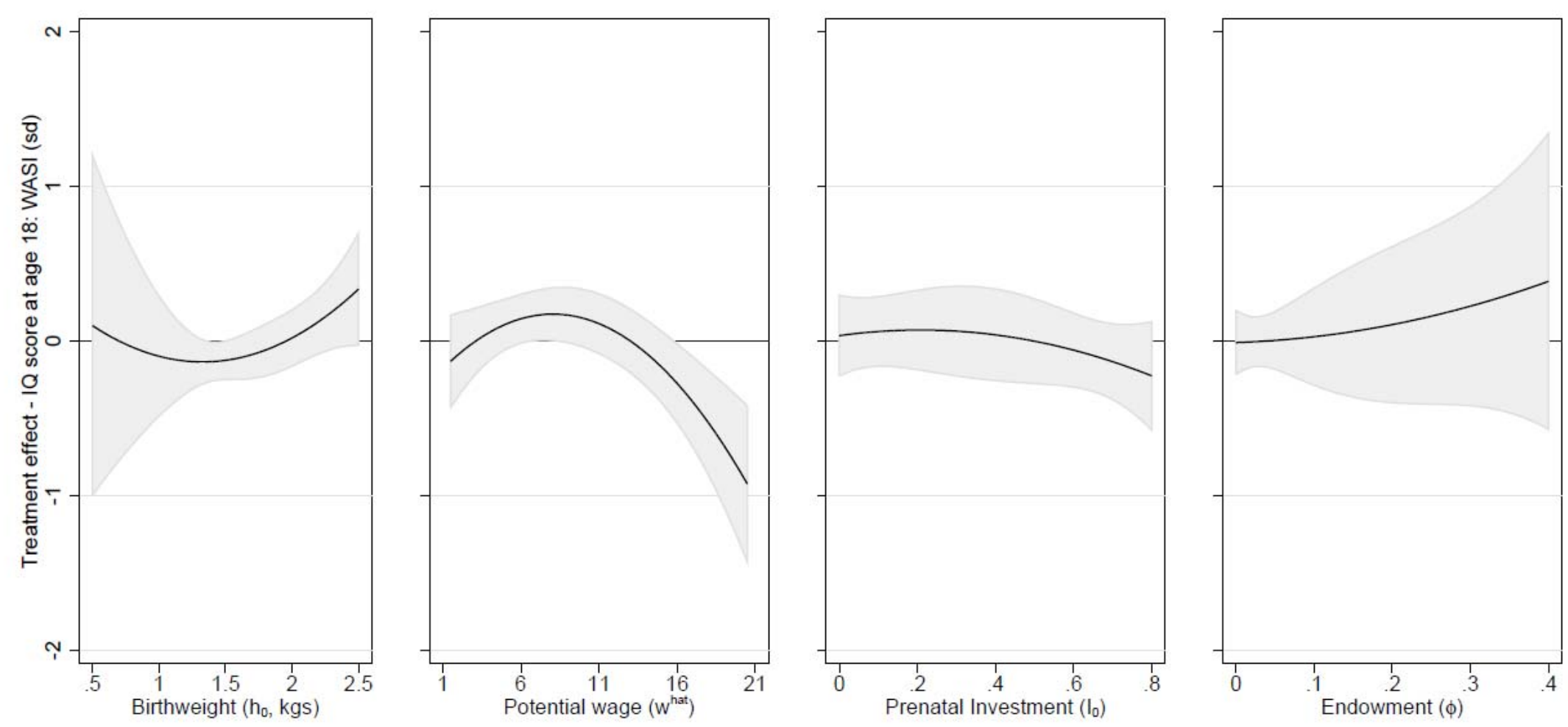

Estimate and 95\% confidence interval. Potential wage: US $\$$ of 2012 per hour. Endowment and Prenatal Investment: percentile in ECLS-B distribution. $\mathrm{N}=582$. 